\title{
Missense dopamine transporter mutations associate with adult parkinsonism and ADHD
}

\author{
Freja H. Hansen, ${ }^{1}$ Tina Skjørringe, ${ }^{2}$ Saiqa Yasmeen, ${ }^{2}$ Natascha V. Arends, ${ }^{1}$ \\ Michelle A. Sahai, ${ }^{3}$ Kevin Erreger, ${ }^{4}$ Thorvald F. Andreassen, ${ }^{1}$ Marion Holy, ${ }^{5}$ Peter J. Hamilton, ${ }^{4}$ \\ Viruna Neergheen, ${ }^{6}$ Merete Karlsborg, ${ }^{7}$ Amy H. Newman, ${ }^{8}$ Simon Pope, ${ }^{6}$ Simon J.R. Heales, ${ }^{6,9}$ \\ Lars Friberg, ${ }^{7}$ Ian Law, ${ }^{10}$ Lars H. Pinborg, ${ }^{11}$ Harald H. Sitte, ${ }^{5}$ Claus Loland, ${ }^{1}$ Lei Shi, ${ }^{3}$

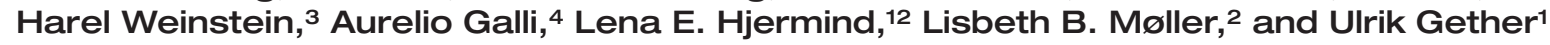

\begin{abstract}
${ }^{1}$ Molecular Neuropharmacology and Genetics Laboratory, Department of Neuroscience and Pharmacology, Faculty of Health and Medical Sciences, University of Copenhagen, Copenhagen, Denmark. ${ }^{2}$ Center for Applied Human Genetics, Kennedy Center,

Copenhagen University Hospital, Glostrup, Denmark. ${ }^{3}$ Department of Physiology and Biophysics, Weill Medical College of Cornell University, New York, New York USA. ${ }^{2}$ Department of Molecular Physiology and Biophysics, Vanderbilt University, Nashville, Tennessee, USA. ${ }^{5}$ Medical University of Vienna, Center for Physiology and Pharmacology, Institute of Pharmacology, Vienna, Austria.

${ }^{6}$ Neurometabolic Unit, National Hospital for Neurology and Neurosurgery, London, United Kingdom. ${ }^{7}$ Department of Neurology, Bispebjerg Hospital, Copenhagen University Hospital, Denmark. ${ }^{8}$ National Institute on Drug Abuse-Intramural Research Program, $\mathrm{NIH}$, Baltimore, Maryland, USA. ${ }^{9}$ Chemical Pathology, Great Ormond Street Hospital for Children, London, United Kingdom.

${ }^{10}$ Department of Clinical Physiology, Nuclear Medicine and PET, Rigshospitalet, and ${ }^{11}$ Neurobiology Research Unit, Epilepsy Clinic, Copenhagen University Hospital, Copenhagen, Denmark. ${ }^{12}$ Danish Dementia Research Centre, Clinic of Neurogenetics,

Department of Neurology, Rigshospitalet, Copenhagen University Hospital and Department of Cellular and Molecular Medicine, Section of Neurogenetics, Faculty of Health and Medical Sciences, University of Copenhagen, Copenhagen, Denmark.
\end{abstract}

\begin{abstract}
Parkinsonism and attention deficit hyperactivity disorder (ADHD) are widespread brain disorders that involve disturbances of dopaminergic signaling. The sodium-coupled dopamine transporter (DAT) controls dopamine homeostasis, but its contribution to disease remains poorly understood. Here, we analyzed a cohort of patients with atypical movement disorder and identified 2 DAT coding variants, DAT-Ile312Phe and a presumed de novo mutant DAT-Asp421Asn, in an adult male with early-onset parkinsonism and ADHD. According to DAT single-photon emission computed tomography (DAT-SPECT) scans and a fluoro-deoxy-glucose-PET/MRI (FDG-PET/MRI) scan, the patient suffered from progressive dopaminergic neurodegeneration. In heterologous cells, both DAT variants exhibited markedly reduced dopamine uptake capacity but preserved membrane targeting, consistent with impaired catalytic activity. Computational simulations and uptake experiments suggested that the disrupted function of the DAT-Asp421Asn mutant is the result of compromised sodium binding, in agreement with Asp421 coordinating sodium at the second sodium site. For DAT-Asp421Asn, substrate efflux experiments revealed a constitutive, anomalous efflux of dopamine, and electrophysiological analyses identified a large cation leak that might further perturb dopaminergic neurotransmission. Our results link specific DAT missense mutations to neurodegenerative early-onset parkinsonism. Moreover, the neuropsychiatric comorbidity provides additional support for the idea that DAT missense mutations are an ADHD risk factor and suggests that complex DAT genotype and phenotype correlations contribute to different dopaminergic pathologies.
\end{abstract}

\section{Introduction}

Dopamine is an important neurotransmitter regulating motor activity, cognition, neuroendocrine functions, and reward mechanisms. Moreover, disturbances in dopaminergic signaling are of central importance in several common brain diseases including parkinsonism, attention deficit hyperactivity disorder (ADHD), autism, schizophrenia, and addiction $(1,2)$. However, the pathophysiology of these diseases is still poorly understood. Importantly, the spatiotemporal regulation of dopaminergic neurotransmission is critically dependent on the presynaptic dopamine transporter (DAT), which mediates reuptake of released dopamine in the synaptic cleft (3-5). Together with several other neurotransmitter carriers, DAT belongs to the family of neurotransmitter/sodium

Authorship note: Freja H. Hansen and Tina Skjørringe, as well as Lena E. Hjermind, Lisbeth B. Møller, and Ulrik Gether, contributed equally to this work.

Conflict of interest: The authors have declared that no conflict of interest exists. Citation for this article: J Clin Invest. 2014;124(7):3107-3120. doi:10.1172/JCI73778. symporters, also referred to as the solute carrier 6 (SLC6) family of sodium-coupled transporters $(3,5)$. The significance of DAT in dopamine homeostasis has been supported by genetic deletion of the DAT gene in mice, resulting in an extracellular hyperdopaminergic state concomitantly with a $95 \%$ reduction in tissue content of dopamine (6). The DAT-knockout (DAT-KO) mice are characterized by severe behavioral changes including spontaneous hyperactivity, as well as by memory and learning deficits (2, 7). Interestingly, both DAT-KO mice and DAT-knockdown mice with $10 \%$ residual DAT expression (8) have been considered animal models of ADHD (9-11). DAT-KO mice might also serve as a model of parkinsonism, although primarily after inhibiting dopamine synthesis with a tyrosine hydroxylase (TH) inhibitor (12, 13). Nevertheless, the significance of altered DAT function in the human diseases remains unclear.

The consequences of DAT deficiency in humans were recently elucidated by the identification of 11 patients, all with homozygous or compound heterozygous missense mutations in the DAT 
gene (SLC6A3). The mutations presumably caused retention of the encoded DAT proteins in the ER and practically eliminated mature DAT protein expression $(14,15)$. The patients presented in infancy with hyperkinetic and/or hypokinetic movement disorder, progressing to severe parkinsonism-dystonia with eye movement disorder and pyramidal tract features (15). Seven of the children were misdiagnosed with cerebral palsy, suggesting that this condition, denoted DAT deficiency syndrome, may be an underappreciated cause of movement disorder in infancy.

Alterations in DAT function have also been linked to psychiatric disorders. As a principle target of frequently prescribed ADHD medications, such as methylphenidate (Ritalin) and amphetamine (e.g., Adderall) $(5,16)$, DAT has received much attention in studies of ADHD, and several genetic association and linkage studies have pointed to a role of DAT in ADHD pathology (17-20). In addition, 2 coding variants in SLC6A3, Ala559Val (DAT-A559V) and Arg615Cys (DAT-R615C), have been identified in patients with ADHD and bipolar disorder (21-23). More recently, a de novo DAT missense mutation, Thr356Met (DAT-T356M), was detected in a patient with autism spectrum disorder (24).

The conceivable contribution of SLC6A3 coding variants to both movement disorder and psychiatric disorders suggests that the character and severity of functional changes in DAT missense mutations might determine the pathological outcomes. To gain insight into the role of SLC6A3 coding variants in human disease, we sequenced coding exons of SLC6A3 in a cohort of patients with early-onset parkinsonism, dystonia, or related atypical movement disorders. Among these, we identified 1 adult patient who was diagnosed with both early-onset parkinsonism and ADHD and who was compound heterozygous for 2 DAT coding variants. One coding variant was transmitted from his father and changes isoleucine in position 312 to phenylalanine (DAT-I321F), whereas the other variant is the result of a presumed de novo mutation that changes aspartate in position 421 to asparagine (DAT-D421N). Molecular characterization in heterologous cells revealed that both mutants have markedly reduced dopamine uptake capacity. For DAT-D421N, uptake is almost eliminated as a likely consequence of disrupted binding of sodium to the second sodium site in DAT. Notably, DATD421N also displays constitutive, anomalous reverse transport of dopamine and possesses a large inward cation leak that might further perturb dopaminergic signaling. To our knowledge, the data from the present study provide the first link between DAT missense mutations and neurodegenerative parkinsonism in adults. The data also reveal the first patient with ADHD who is compound heterozygous for DAT mutations, thereby substantiating that DAT coding variants are risk factors in ADHD. Finally, the results suggest that DAT deficiency syndrome is not restrictively a childhood disease and that residual DAT activity might postpone the onset of parkinsonian symptoms until adulthood.

\section{Results}

Identification of coding DAT variants in an adult male with parkinsonism and $A D H D$. DNA from 91 patients with symptoms of early-onset parkinsonism, dystonia, or other unclassified movement disorders were analyzed for mutations in SLC6A3 exons (primer sequences are listed in Supplemental Table 1; supplemental material available online with this article; doi:10.1172/JCI73778DS1). In 1 patient, we identified 2 unique missense mutations, c.934A>T in exon 7 and c.1261G>A in exon 9, which gave rise to the amino acid substitutions Ile312Phe (DAT-I321F) and Asp421Asn (DATD421N), respectively (Figure 1, A and B). The mutations were not registered as polymorphisms in variant databases including the Exome Variant Server (NHLBI GO Exome Sequencing Project [ESP]; http://evs.gs.washington.edu/EVS/; accessed March, 2014) and Ensemble (http://Jun2013.archive.ensembl.org/index.html), which include sequence information for more than 13,000 alleles. Moreover, the mutations were not detected upon analysis of 400 Danish control alleles (data not shown). None of the mutations could be identified in the mother, whereas an unaffected sister carried the DAT-I312F mutation (Figure 1C). Hence, the DAT-I312F allele was presumably transmitted to the siblings from the recently deceased father, while DAT-D421N appears to be a de novo mutation. Sequence alignment revealed both Ile312 and Asp421 as evolutionarily highly conserved (Figure 1D).

To determine the cis-trans allelic position of the mutations, we took advantage of an SNP (c.1215A>G) in exon 9 that cosegregated with the I312F mutation. We designed sequence-specific primers that selectively recognized either the D421N mutation (c.1261G>A), the SNP cosegregating with the I312F mutation (c.1215A>G), or the corresponding WT DNA sequences (Supplemental Figure 1). PCR amplification of genomic DNA from the proband, his sister and mother, showed a pattern consistent with a biallelic position of the $\mathrm{D} 421 \mathrm{~N}$ and the $1215 \mathrm{~A}>\mathrm{G}$ SNP representing the I312F mutation, as we did not observe any amplification of proband DNA when using the D421N and the SNP selective primers together (Supplemental Figure 1). We also applied the mutation and SNP-specific primers, together with intron-spanning primers, to amplify the proband's 2 DNA strands for sequencing and consistently observed that the D $421 \mathrm{~N}$ mutation and the $1215 \mathrm{~A}>\mathrm{G}$ SNP were not detected on the same allele (Supplemental Figure 1). Altogether, the data provide strong evidence for a trans-allelic position of the $\mathrm{I} 312 \mathrm{~F}$ and $\mathrm{D} 421 \mathrm{~N}$ mutations in the patient. In addition to the DAT-I312F and DAT-D421N mutations, 3 previously reported SNPs were identified in the cohort: c. $114 \mathrm{~A}>\mathrm{G}$ (rs6350) with a frequency of $13 \%, \mathrm{c} .1215 \mathrm{~A}>\mathrm{G}$ (rs6347) with a frequency of $40 \%$, and c.1857G $>C$ (rs200712598) with a frequency of less than $1 \%$.

The patient is a male of mixed European descent (aged 40 years at the time of referral) with early-onset parkinsonism and psychiatric symptoms without a family history of movement disorders or psychiatric disease. He suffered from unspecified failure to thrive in infancy and learning problems in school. He was not tested or examined by experts in child psychiatry during childhood or adolescence, but intellectual impairment and behavioral problems with learning difficulties and lack of impulse control were evident to relatives and to school and recreational center staff from early childhood. At age 28, he had insidious onset of rightsided hand tremor. At this time, normal biochemistry excluded disorders such as Wilson's disease, and a CT brain scan as well as electroencephalography were normal. An apomorphine test resulted in a marked reduction in tremor, but a following therapeutic trial with levodopa treatment was not sufficiently effective to attenuate the tremor and therefore did not support the tentative diagnosis, dopa-responsive dystonia. The patient had a progressive disease course over the following years. Treatment with levodopa was attempted, with minor alleviation of symptoms but concomitant with considerable side effects. At age 35, he had severe coarse tremor in all extremities, truncus, and head during action as well as at rest, accompanied by rigidity and bradykinesia. 

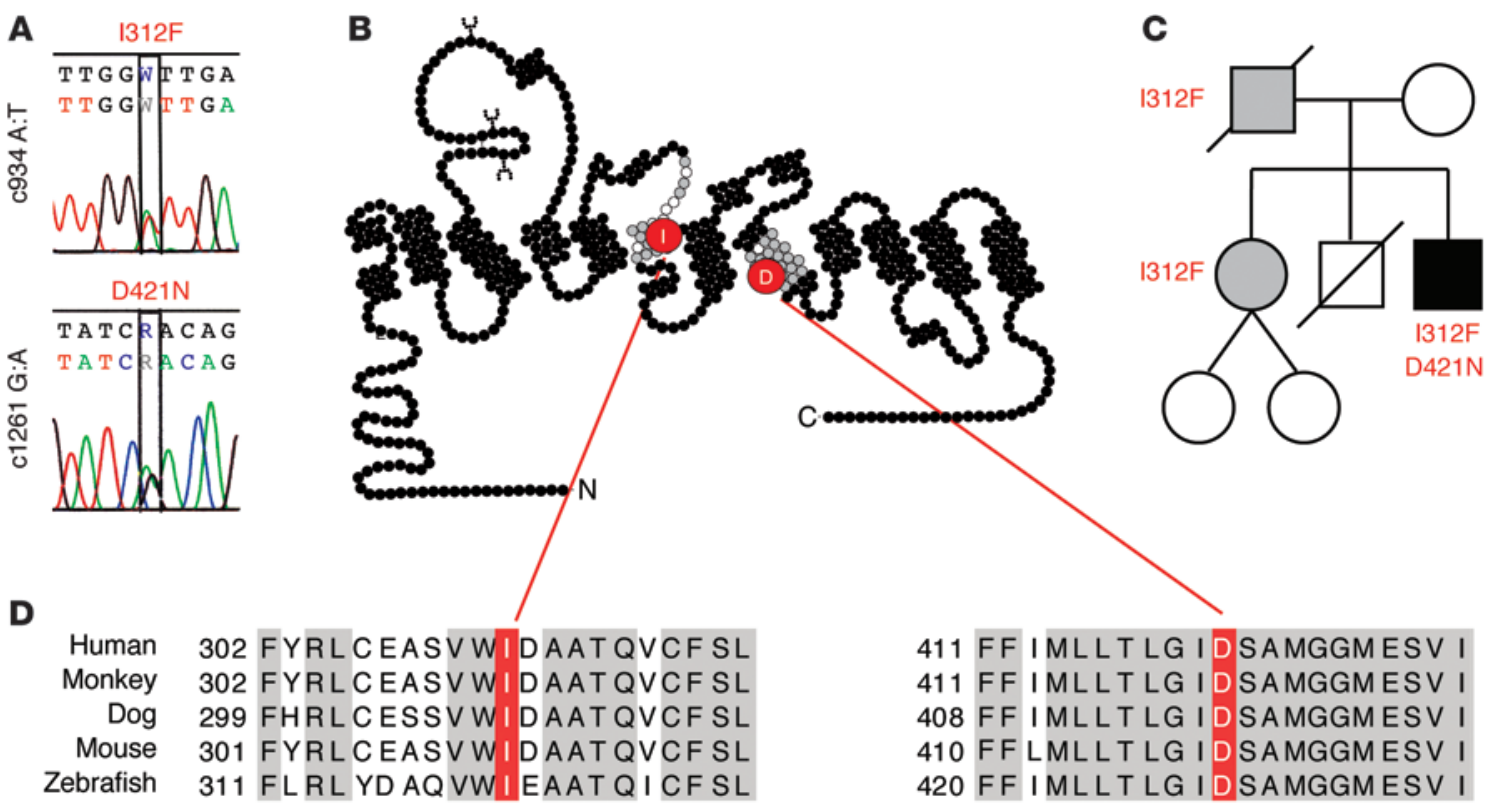

411 FF I MLLT LG IDSAMGGMESV I

411 FF IMLLTLG I DSAMGGMESV I

408 FF I MLLT LG I DSAMGGMESV I

410 FF LMLLT LG I DSAMGGMESV I

420 FF I MLLT LG IDSAMGGMESV I

\section{Figure 1}

Identification of missense mutations in SLC6A3. (A) Identified mutations in SLC6A3. Upper panel: nucleotides c.930-938; the c934 A:T mutation, giving rise to DAT-I312F, is denoted as W. Lower panel: nucleotides c.1257-1265; the c1261 G:A mutation, giving rise to DAT-D421N, is denoted as R. (B) Snake diagram of DAT sequence illustrating the location of I312 and D421 in TMs 6 and 8, respectively. (C) Family tree of the patient. The affected patient is indicated by the black square. An unaffected sister also carries the I312F variant (indicated by the gray circle). The mother carries only WT DAT. The diseased father was not available for testing, but was presumably a carrier of the I312F allele (indicated by the gray square). Females are indicated by circles and males by squares. (D) Sequence alignment of 5 vertebrate species showing conservation of I312 as well as D421.

Huntington's disease-like syndrome and parkinsonism were suspected, but our search for extended trinucleotide repeats in $H T T$, ATXN1-3, CACNA1A, and TBP, mutations in PRKN and GCH1, a hotspot mutation in LRRK2 (Gly2019Ser), and most of the common point mutations and copy number variations in $D J 1, P I N K$, UCHL1, SNCA, and ATP13A2 were all negative. Treatment with the anticholinergic drug orphenadrine $(150 / 150 / 100 / 0 \mathrm{mg})$ was initiated and is hitherto ongoing, with some positive effects in controlling tremor and rigidity. After repeated self-injury behavior, the patient was psychiatrically assessed at age 39 years and diagnosed with ADHD according to DSM-IV (Diagnostic and Statistical Manual of Mental Disorders, fourth edition, American Psychiatric Association, Washington, DC, USA) criteria. Treatment with methylphenidate (Ritalin) produced unacceptable side effects. Symptoms were alleviated according to his caregivers, but not according to the patient.

Presently, the patient has universal tremor (Supplemental Video 1) as well as bradykinesia and rigidity in the upper and lower limbs (Supplemental Videos 2 and 3, respectively). He demonstrates normal-pursuit eye movements, including complete range, and no square wave jerks are seen, but he has saccades with increased latency in initiation, suppressible head movements to initiate, and moderate slowing of movement velocity (Supplemental Video 4). A retropulsion pull test was positive (Supplemental Video 5). Of note, the videos were recorded with the patient on anticholinergic treatment.

To assess possible neurodegeneration in the dopaminergic pathways of the patient, 2 DAT-SPECT scans were performed with an interval of 8 years (2005 and 2013). While both scans showed bilat- eral reduction of [ $\left.{ }^{123} \mathrm{I}\right]$-FP-CIT binding to DAT in the striatum, DAT availability was further reduced during the 8-year period from approximately $35 \%$ to $15 \%$ compared with the expected value of age-matched controls (Figure 2A). Moreover, a combined ${ }^{18} \mathrm{~F}-$-fluorodeoxyglucose $\left(\left[{ }^{18} \mathrm{~F}\right]-\mathrm{FDG}\right) \mathrm{PET} / \mathrm{MRI}$ scan was performed in 2013. $\left[{ }^{18} \mathrm{~F}\right]-$ FDG PET showed slight to moderate metabolic reductions cortically in the occipitotemporal junctions bilaterally and intact metabolic activity in the striatum (Figure 2B). MRI volumetric measurements, however, showed a significantly reduced volume of the caudate nuclei after correction for the intracranial volumes (left: $0.195 \%$; right: $0.184 \%$; less than $-3 \mathrm{SD}$ ). The corrected putaminal volumes were also reduced (left: $0.30 \%$; right: $0.28 \%)$, though not significantly (-1.5 SD). Together, these data support a neurodegenerative component of the patient's disease. Note that despite volume reductions, intact striatal metabolic activity is the common finding, also in late Parkinson's disease (PD), while cortical reductions may be even more pronounced than those found in this patient (25). Finally, we assessed the level of monoamine metabolites in the cerebrospinal fluid (CSF). The analysis revealed a homovanillic acid (HVA) concentration of $268 \mathrm{nmol} / \mathrm{l}$ (reference range, 71-565) and a 5-hydroxyindoleacetic acid (5HIAA) concentration of $104 \mathrm{nmol} / 1$ (reference range, 58-220), thus an HVA/5HIAA ratio of 2.6 (reference range, 1.0-3.7).

DAT-I312F and DAT-D421N exhibit impaired dopamine uptake capacity. To search for evidence that DAT-I312F and DAT-D421N contribute to the phenotypic characteristics of the patient, we assessed $\left[{ }^{3} \mathrm{H}\right]$-dopamine uptake in HEK293 cells transiently transfected with cDNA encoding WT DAT (WT), DAT-I312F, or DAT-D421N. We observed a markedly reduced transport capac- 
A

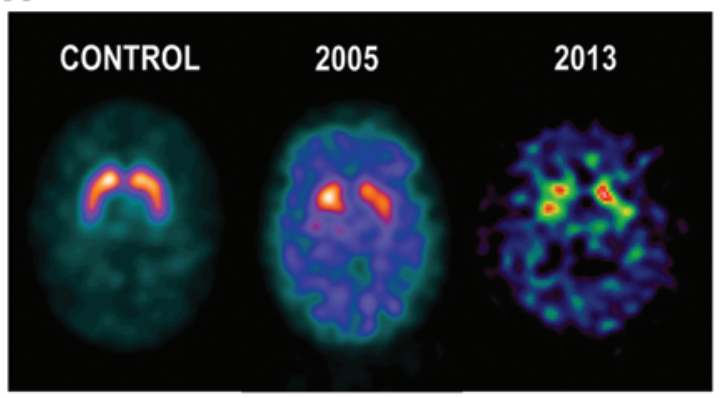

B

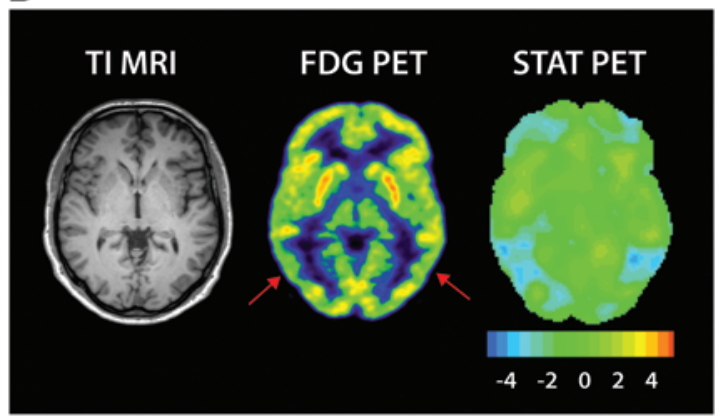

Figure 2

Nuclear brain imaging with SPECT and FDG PET. (A) SPECT imaging of DAT. The figure shows images of [123|]FP-CIT binding to DAT in a healthy control (left) and in the proband at 34 years of age (middle) and 43 years of age (right). DAT availability in the striatum, i.e., the ratio of specifically bound radioligand to that of nondisplaceable radioligand, was severely reduced bilaterally and was approximately $35 \%$ in 2005 and $15 \%$ in 2013 of the expected value in a group of age-matched controls. (B) Transaxial sections through the striatum of the proband with coregistered T1-weighted MRI (left), [ $\left.{ }^{18} \mathrm{~F}\right]-\mathrm{FDG}$ PET (middle), and quantitative statistical comparisons of [18F]-FDG PET (right) with healthy controls showing preserved metabolic activity in the basal ganglia with a slight to moderate reduction ( $-4 \mathrm{SD}$; see color scale) in the occipitotemporal junction (red arrows).

ity for DAT-I312F ( $\mathrm{V}_{\max } \sim 56 \%$ of WT), with no significant change in $K_{\mathrm{m}}$ (Figure 3, A and B). DAT-D421N-mediated uptake was almost eliminated, and $\mathrm{V}_{\max }$ and $K_{\mathrm{m}}$ values could not be reliably determined, because the data could not be fitted by MichaelisMenten kinetics. However, at $6.4 \mu \mathrm{M}$ of dopamine, DAT-D421N exhibited approximately $10 \%$ uptake activity compared with that of WT (Figure 3, A-C). The uptake capacity of cells cotransfected with DAT-I312F and DAT-D $421 \mathrm{~N}$ was approximately $30 \%$ of WT both when calculating $\mathrm{V}_{\max }$ (Figure $3 \mathrm{~B}$ ) and when assessing uptake at $6.4 \mu \mathrm{M}$ of dopamine (Figure 3C). Accordingly, the uptake was approximately $50 \%$ of DAT-I312F alone (Figure 3, A and $\mathrm{B}$ ), indicating that DAT-D421N does not exhibit a dominant negative effect on DAT-I312F.

Next, we determined the ability of the mutants to bind the high-affinity cocaine analog $\left[{ }^{3} \mathrm{H}\right]-\mathrm{CFT}\left(\left[{ }^{3} \mathrm{H}\right]-2 \beta\right.$-carbomethoxy-3 $\beta$ (4-fluorophenyl)tropane) using transiently transfected COS-7 cells. Whereas DAT-I312F showed binding properties similar to those of WT, we could detect no binding to DAT-D421N (Figure 3D). We also performed the binding experiments in HEK293 cells and obtained very similar results, although nonspecific binding of $\left[{ }^{3} \mathrm{H}\right]$-CFT to these cells was much higher (Supplemental Figure 2).
Next, we investigated the cellular processing of the mutants by Western blotting and surface biotinylation. WT DAT expressed in heterologous cells can be found in a mature, fully glycosylated form that elutes at approximately $85 \mathrm{kDa}$ and as an immature ER-glycoform of approximately $55 \mathrm{kDa}$ that is absent from the cell surface (26-28). Consistent with the preserved binding properties of DAT-I312F, Western blot analysis of whole-cell lysates from HEK293 cells showed no reduction compared with WT in the amount of fully glycosylated, mature transporters (Supplemental Figure 3). Likewise, surface biotinylation experiments showed no difference in surface expression of DAT-I312F compared with that in WT (Figure 4, A and B). Interestingly, despite the dramatic reduction we observed in uptake capacity and the absence of measurable $\left[{ }^{3} \mathrm{H}\right]$-CFT binding, both Western blot analysis and surface biotinylation showed a significant increase in the levels of mature transporters for DAT-D421N (Supplemental Figure 3 and Figure 4, A and B).

We further assessed the cellular distribution of DAT-I312F and DAT-D $421 \mathrm{~N}$ by immunostainings and confocal microscopy analysis of transfected HEK293 cells (Supplemental Figure 4) and transfected CAD cells (Figure 5), a CN-derived catecholaminergic cell line without endogenous DAT expression (29). Both DAT-I312F and DAT-D421N showed cellular distributions similar to those of WT, with clear plasma membrane staining as well as staining of intracellular structures (Figure 5A and Supplemental Figure 4). To visualize only surface-expressed transporters, we used our recently developed fluorescent cocaine analog JHC 1-64, which binds to correctly folded transporters expressed at the cell surface $(30,31)$. Following incubation with $10 \mathrm{nM} \mathrm{JHC}$ 1-64 and subsequent washing, we observed a strong membrane labeling of cells transfected with WT or DAT-I312F, with no apparent difference in intensity. In contrast, we were unable to detect any membrane staining of DAT-D $421 \mathrm{~N}$-transfected cells when using $10 \mathrm{nM}$ JHC 1-64 (Figure 5B). However, following incubation with $300 \mathrm{nM} \mathrm{JHC} \mathrm{1-64,} \mathrm{we} \mathrm{observed} \mathrm{a}$ strong membrane labeling of DAT-D $421 \mathrm{~N}$-transfected cells, indicative of a reduced JHC 1-64 affinity for DAT-D421N (Figure 5C). Importantly, labeling at this high JHC 1-64 concentration was blocked by preincubation with nomifensine, a selective DAT blocker (Figure 5D). In summary, both DAT-I312F and DAT-D421N are efficiently targeted to the plasma membrane despite marked functional impairment.

DAT-D421N disrupts the second sodium binding site in DAT. According to a homology model of DAT (Figure 6A), based on the structure of the prokaryotic DAT homolog LeuT (32), Ile312 is located in transmembrane (TM) segment 6 , without any direct contacts with the substrate or the bound ions (Figure 6B). However, Asp421 aligns with Thr354 in LeuT, a residue that coordinates the sodium ion bound at the second sodium-binding site (Na2). Similarly, Asp421 coordinates the second sodium ion in our DAT model (Figure 6C). The validity of this model is supported by the newly published structure of Drosophila DAT, in which sodium in $\mathrm{Na} 2$ is coordinated in a trigonal bipyramidal fashion by residues in TMs 1 and 8, including Asp420, which corresponds to Asp421 in human DAT (hDAT) (33). To address the consequences of the Asp421Asn mutation on sodium binding, we compared the free energy of binding of $\mathrm{Na} 2$, calculated for both WT and DAT-D421N bound to dopamine and ions $(34,35)$. The structural basis for these results encompasses a change in the $\mathrm{Na} 2$ binding site, which in WT involves Gly75, 
A

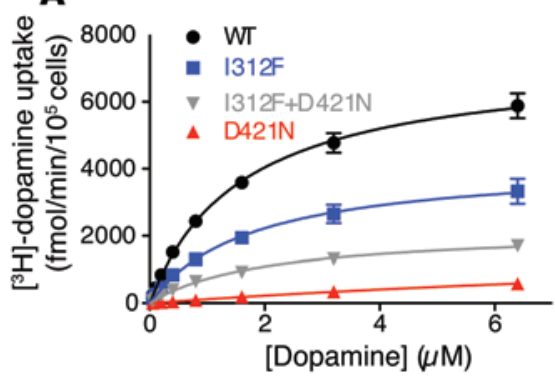

B

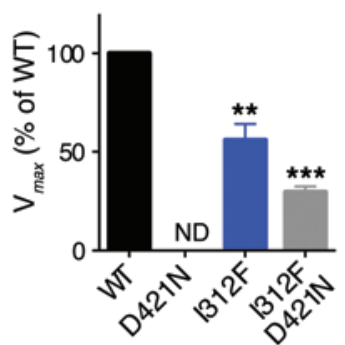

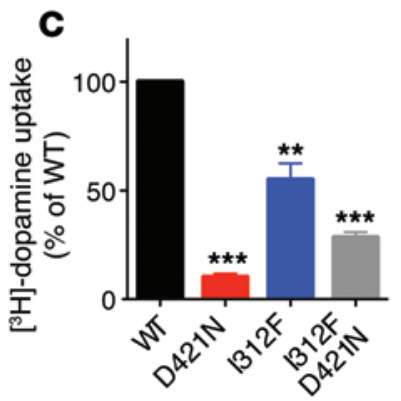

D

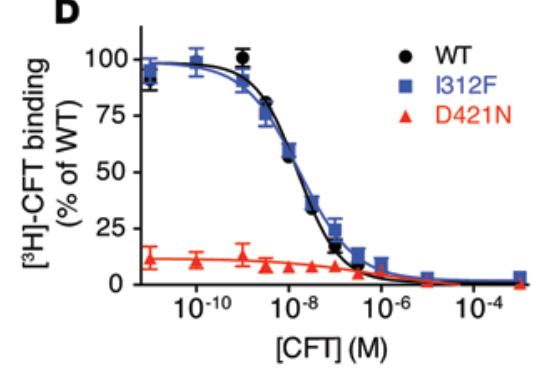

Figure 3

Functional characterization of DAT-I312F and DAT-D421N by $\left[{ }^{3} \mathrm{H}\right]$-dopamine uptake and $\left[{ }^{3} \mathrm{H}\right]$-CFT-binding experiments. $(\mathbf{A})\left[{ }^{3} \mathrm{H}\right]$-dopamine uptake in transiently transfected HEK293 cells. The curves represent average curves from 6 independent experiments, each with triplicate uptake determinations (5 minutes) at the indicated dopamine concentrations. (B) $\mathrm{V}_{\max }$ values of $\left[{ }^{3} \mathrm{H}\right]$-dopamine uptake compared with WT. In each experiment, the $\mathrm{V}_{\max }$ values of mutants were normalized to WT. Michaelis-Menten kinetics was applied to fit data. ${ }^{*} P<0.01$ and ${ }^{* \star \star} P<0.0001$ by 1 -sample $t$ test; $n=6$. Uptake by DAT-D421N could not be fitted reliably by Michaelis-Menten kinetics and is therefore denoted as not determined (ND). $K_{\mathrm{m}}$ values were fitted to $1.7 \pm 0.3 \mu \mathrm{M}$ for $\mathrm{WT} ; 1.8 \pm 0.4 \mu \mathrm{M}$ for DAT-I312F; and $2.1 \pm 0.4$ for DAT-I312F plus DAT-D421N. (C) Evaluation of $\left[{ }^{3} \mathrm{H}\right]$-dopamine uptake at $6.4 \mu \mathrm{M}$ of dopamine. The uptake was normalized to WT for each experiment. ${ }^{* *} P<0.01$ and ${ }^{* * *} P<0.0001$ by 1 -sample $t$ test; $n=6$. (D) $\left[{ }^{3} \mathrm{H}\right]$-CFT binding to transiently transfected COS-7 cells. Curves represent the averages of 4 experiments, each performed in triplicate. Binding data were fitted by nonlinear regression and normalized to WT in each experiment. While DAT-I312F shows preserved binding properties $\left(K_{d}\right.$ values [SE intervals] for DAT-I312F and WT were 16.9 [12.1-23.6] nM and 13.7 [12.7-14.8] nM, respectively), no specific binding to DAT-D421N was detected. All data are the means \pm SEM. $B_{\max }$ for WT was $149 \pm 39 \mathrm{fmol} / 105$ cells.

Phe76, Val78, Asp421, and Ser422, whereas in DAT-D421N, it is changed to Gly75, Val78, Leu418, and Asn421. In WT, the free energy of sodium binding in $\mathrm{Na} 2$ was more favorable (by $\sim 32 \mathrm{kcal} / \mathrm{mol}$ ) than the solvation energy of sodium in a water box $(-102 \mathrm{kcal} / \mathrm{mol})$, showing a robust affinity of DAT for sodium at this site. In contrast, the corresponding energy for sodium in Na2 of DAT-D421N was calculated to be approximately $-98 \mathrm{kcal}$, i.e., similar to the affinity of sodium for the aqueous solution. Thus, binding of sodium in $\mathrm{Na} 2$ is weakened considerably in DAT-D $421 \mathrm{~N}$ compared with that in WT. Following the recent publication of the crystal structure of the nonfunctional mutant of Drosophila melanogaster dopamine transporter (dDAT, PDB code 4M48), a second de novo model of hDAT was constructed with the new structure as the template (33). This enabled a comparative investigation of homology model quality and features, which showed that the root mean

square deviation between hDAT based on LeuT and dDAT was $1.3 \AA$ for the critical residues in TMs 1,6 , and 8 (Supplemental Figure 5). Thus, the critical regions of the substrate dopamine binding site and ion binding sites, which are key to the inferences we describe, are strikingly similar for both models. Moreover, the full comparison of the original LeuT-based homology model with the ones based on dDAT (Supplemental Figure 5) and also with an additional hybrid model constructed with LeuT as a template for TMs 1-10 and dDAT for TMs 11 and 12 (see Supplemental Figure 6) show good structural agreement and support all conclusions drawn from the molecular dynamics (MD) and free-energy perturbation (FEP) results.

In agreement with the predicted loss of sodium affinity in DAT-D421N, determination of $\left[{ }^{3} \mathrm{H}\right]$-dopamine uptake in transected HEK293 cells at increasing sodium concentrations (using $\mathrm{ChoCl}$ as a substitute) suggested strong impairment of sodium binding to DAT-D421N, with no sign of uptake saturation at a sodium concentration up to $200 \mathrm{mM}$ (Figure 6D). In contrast, DAT-I312F displayed only a small change in sodium dependency in the uptake experiments $\left(\mathrm{EC}_{50}=70 \pm 20 \mathrm{mM}\right.$ for DAT$\mathrm{I} 312 \mathrm{~F}$ vs. $\mathrm{EC}_{50}=30 \pm 4 \mathrm{mM}$ for WT; $n=3$, means $\pm \mathrm{SEM}$ ). The sodium dependency of $\left[{ }^{3} \mathrm{H}\right]$-CFT binding was also preserved for DAT-I312F in COS-7 cells (Figure 6E, $\mathrm{EC}_{50}=29 \pm 3.6 \mathrm{mM}$ for DAT-I312F vs. $\mathrm{EC}_{50}=46 \pm 10 \mathrm{mM}$ for WT; $n=4$, means \pm SEM) and in HEK293 cells (EC50 = $25 \pm 5.3 \mathrm{mM}$ for DAT-I312F vs. $\mathrm{EC}_{50}=30 \pm 2.5 \mathrm{mM}$ for WT; $n=5-7$, means \pm SEM. Data not shown).

DAT-D421N exhibits anomalous dopamine efflux. Amphetamine is a DAT substrate and is capable of promoting the reversal of dopamine transport, which is believed to play a critical role in its psychostimulatory effect (36-39). To further characterize the functional consequences of the Ile312Phe and Asp421Asn mutations, we assessed amphetamine-induced dopamine efflux by amperometry. As expected, amphetamine caused a large transient increase in the amperometric signal for WT, reflecting oxidation of the released dopamine. We observed a similar response for DAT-I312F, while strikingly different properties were seen once more for DAT-D $421 \mathrm{~N}$, with amphetamine causing a reduction instead of an increase in the amperometric signal (Figure 7, A-C). To further substantiate this finding, we also assessed amphetamine-induced efflux in a $\left[{ }^{3} \mathrm{H}\right] \mathrm{MPP}^{+}$superfusion assay. HEK293 cells were preloaded with the metabolically inert DAT substrate $\left[{ }^{3} \mathrm{H}\right] \mathrm{MPP}^{+}$, and in agreement with the amperometry studies, amphetamine elicited a clear increase in $\left[{ }^{3} \mathrm{H}\right] \mathrm{MPP}^{+}$efflux in the WT and DATI312F-expressing cells, while no amphetamine-induced efflux was apparent for cells expressing DAT-D421N. Rather, we observed a relative decrease in $\left[{ }^{3} \mathrm{H}\right] \mathrm{MPP}^{+}$efflux through DAT-D421N (Figure $7 \mathrm{D})$, similar to the findings in the amperometry experiments. The data most likely reflect a blocking by amphetamine of a constitutive dopamine-MPP ${ }^{+}$efflux through DAT-D421N. If this were the case, a DAT inhibitor would be expected to have the same effect on dopamine-MPP ${ }^{+}$efflux as that of amphetamine on DAT-D421N, and indeed, this was what we observed. Like amphetamine, cocaine elicited a decrease in the amperometric current for DAT-D421N, but not for that of WT (Figure 7, E and F). Correspondingly, 

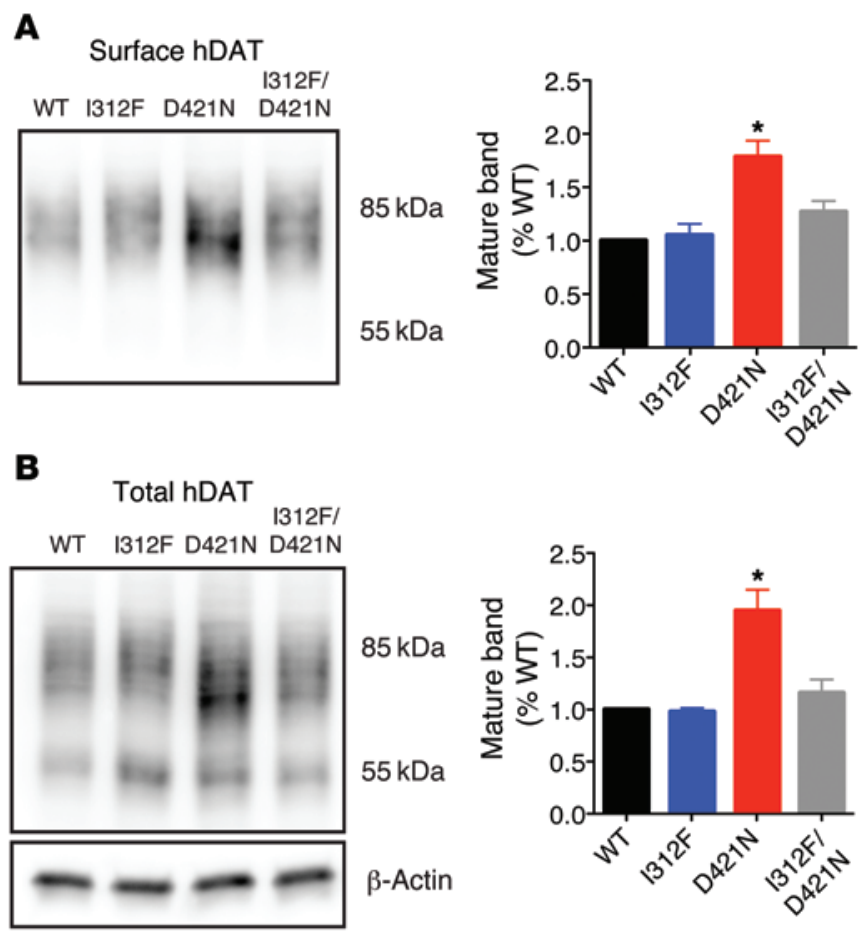

Figure 4

Surface expression of DAT mutants assessed by surface biotinylation. Lysates were made from transiently transfected HEK293 cells. Representative immunoblot of DAT content in biotinylated surface fraction (A) and total protein (B). Right panels show percentage quantifications of the mature DAT glycoforms in the respective fractions compared with WT. DAT-D421N had significantly increased levels of the mature glycoforms compared with WT, whereas mature DAT-I312F levels were similar to those of WT. Data are the means \pm SEM; ${ }^{*} P<0.05$ by 1 -sample $t$ test; $n=5$. Full, uncut gels are shown in the Supplementary Material.

we found that cocaine significantly reduced $\left.{ }^{3} \mathrm{H}\right] \mathrm{MPP}^{+}$efflux in HEK293 cells transiently expressing DAT-D421N (Figure 7G).

DAT-D421N possesses a large cation leak. We also sought to uncover the functional consequences of the mutations through a basal electrophysiological characterization using the 2-electrode voltage clamp technique in Xenopus oocytes. Previous studies of WT DAT have shown that stimulation with dopamine gives rise to an inward current at negative potentials, believed to represent the stoichiometrically coupled current plus an uncoupled flux of anions (40-42). As might be expected from the uptake properties of the 2 mutants, we observed a dopamine-stimulated inward current for DAT-I312F, but not for DAT-D421N (data not shown). Next, we evaluated whether the mutants showed changes in DAT leak conductances. WT DAT has been shown to possess a small and hardly detectable cocaine-sensitive inward cation leak in sodium that becomes much larger in lithium (40) (Figure $8 \mathrm{~A})$. We observed similar properties for DAT-I312F, with a large cocaine-sensitive current in lithium and no detectable cocainesensitive current in sodium (Figure 8B). The properties of DATD $421 \mathrm{~N}$, however, were markedly different. We observed a striking cocaine-sensitive leak current in sodium that was similar in size to that of the current in lithium and that had a similar reversal potential (Figure 8C). Furthermore, the leak in lithium showed a leftward shift in the reversal potential and a more pronounced outward current at positive potentials as compared with WT DAT (Figure 8C). Ion substitutions with $\mathrm{ChoCl}$ and $\mathrm{Na}$-gluconate demonstrated that the leak current was carried, at least in part, by sodium. That is, the reversal potential changed markedly by substituting sodium with choline (Supplemental Figure 7), while the reversal potential barely changed by shifting from chloride to gluconate, indicating that the current was not carried by anions (Supplemental Figure 7).

\section{Discussion}

We describe an adult male with early-onset parkinsonism and neuropsychiatric disorder, who is compound heterozygous for 2 SLC6A3 missense mutations: DAT-I312F and DAT-D421N. DAT$\mathrm{I} 312 \mathrm{~F}$ was inherited from his deceased father, while the DATD $421 \mathrm{~N}$ mutant presumably is a de novo mutation. Importantly, there is increasing awareness that de novo mutations may comprise a considerable segment of the etiology of complex brain disorders (43-45), and, to our knowledge, this patient represents the first case of parkinsonism as well as ADHD, in which a de novo mutation has been identified in DAT. Both mutations, but in particular DAT-D421N, have deleterious consequences for the transporter function, supporting the idea that mutations in SLC6A3 can be a rare monogenetic cause of early-onset atypical parkinsonism and possibly ADHD. In general, $5 \%-10 \%$ of parkinsonism cases can be attributed to monogenetic causes, giving rise to both dominant and recessive modes of inheritance (46). The most common cause of early-onset parkinsonism is mutation in parkin, which is estimated to account for $1.4 \%$ to $8.2 \%$ of early-onset cases $(46,47)$.

DAT deficiency syndrome was recently described as an autosomal recessively inherited disease, manifesting in childhood, typically early infancy, with parkinsonism-dystonia $(14,15,48)$. Mutations in SLC6A3 that probably lead to ER retention of the encoded DAT proteins were identified as the cause of disease. According to our cellular analyses, the DAT mutants carried by the present patient showed markedly different properties, with no signs of ER retention. For DAT-D421N, we even observed increased levels of the mature transporter glycoform. Moreover, confocal imaging and biotinylation experiments demonstrated efficient targeting of DAT-I312F and DAT-D421N to the plasma membrane. Nevertheless, both mutants, and in particular DAT-D421N, displayed impaired uptake capacity. Despite a reduced uptake capacity, DAT-I312F bound the cocaine analog $\left[{ }^{3} \mathrm{H}\right]$-CFT indistinguishably from that in WT and showed little change in sodium affinity, suggesting that mutation of isoleucine in position 312 to phenylalanine is likely to cause a structural perturbation that indirectly impacts catalytic activity without altering expression and folding of the transporter. In contrast, DAT-D421N showed no detectable $\left[{ }^{3} \mathrm{H}\right]$-CFT-binding activity. It is conceivable that this is caused by decreased CFT affinity, preventing the detection of specific binding. Notably, we obtained evidence for decreased affinity of the fluorescent cocaine analog JHC 1-64, i.e., $300 \mathrm{nM}$ was required to visualize DAT-D $421 \mathrm{~N}$ at the plasma membrane of transfected cells. The decreased affinity of these inhibitors, as well as the impaired dopamine uptake, is undoubtedly the result of vastly compromised binding of sodium to DAT-D $421 \mathrm{~N}$, as supported by our functional studies, computational simulations, and by the recent crystal structure of Drosophila DAT, confirming the participation of the aspartate in sodium coordination (33). DAT is suggested, like LeuT, to possess 2 sodium sites ( $\mathrm{Na} 1$ and $\mathrm{Na} 2$ ) and 
A

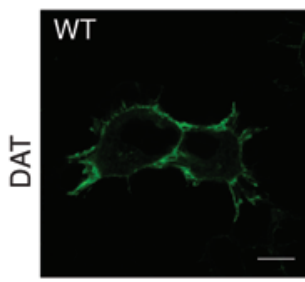

B
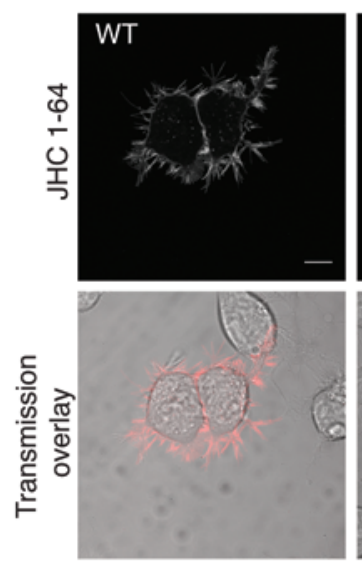

C

Surface DAT 300 nM JHC1-64
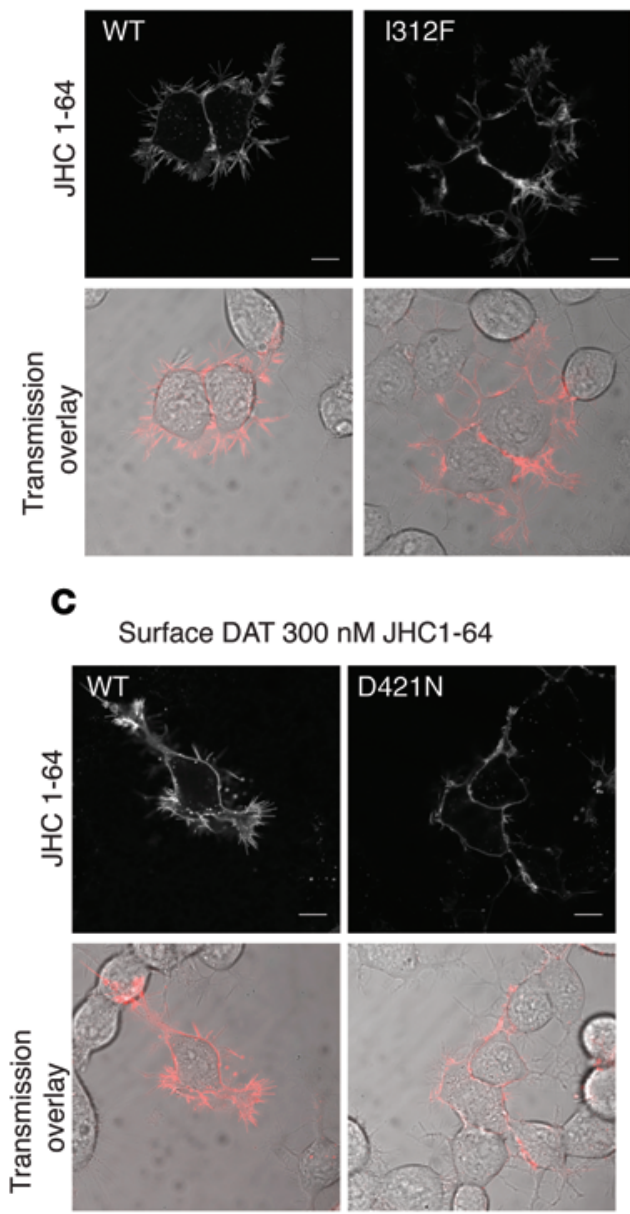

Total DAT
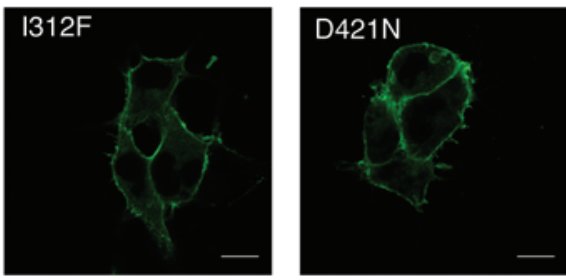

Surface DAT 10 nM JHC1-64
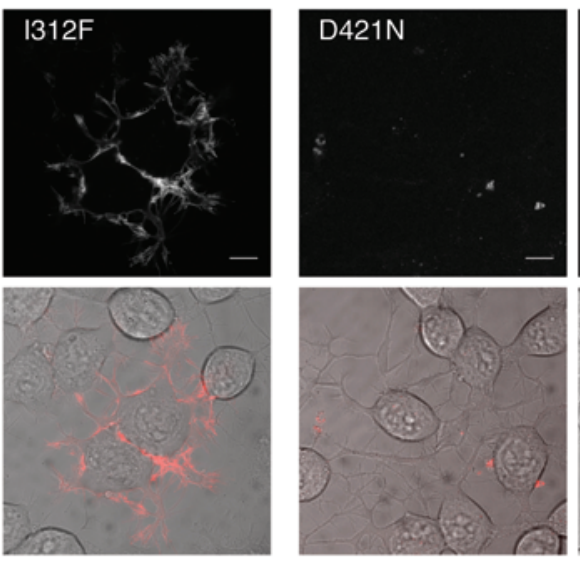
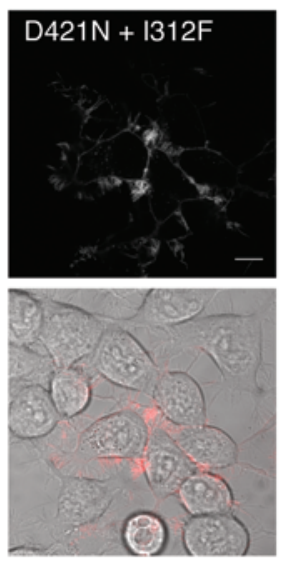

D Surface DAT $300 \mathrm{nM} \mathrm{JHC1-64}$ $+1 \mu \mathrm{M}$ nomifensine
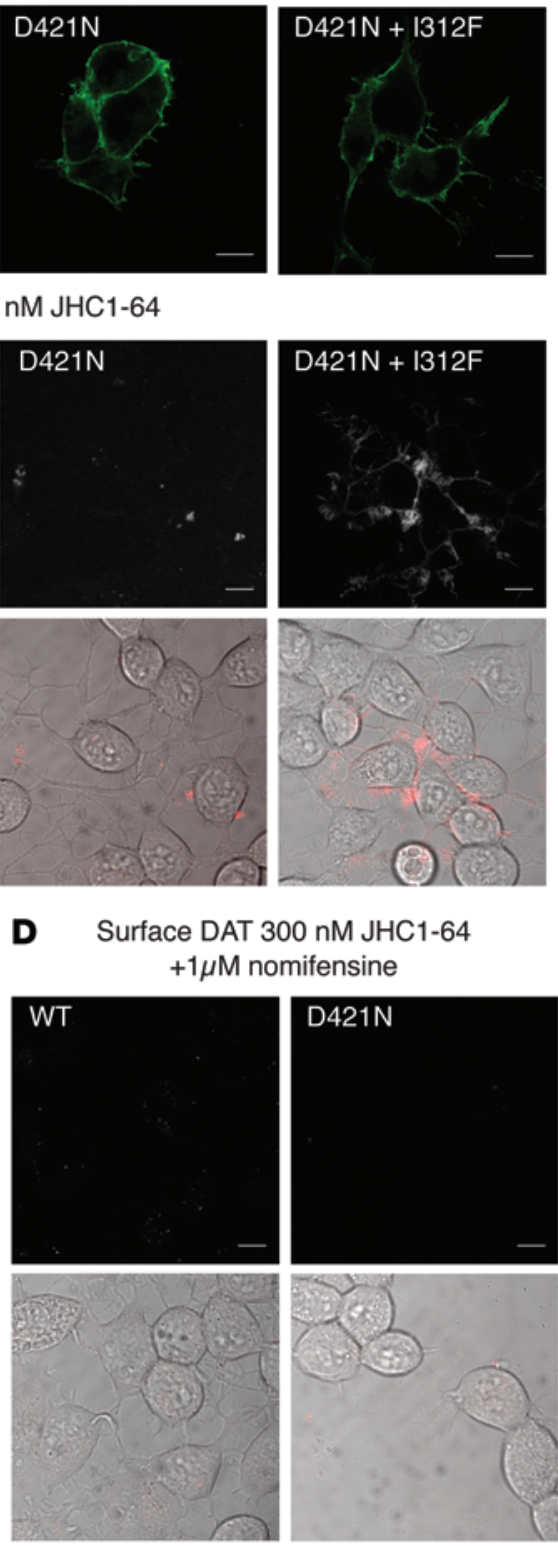

Figure 5

Visualization of DAT mutants by confocal microscopy. (A) Cellular distribution of WT and DAT mutants in transiently transfected CAD cells. DAT was visualized by immunostaining with an $\mathrm{N}$-terminal antibody. No differences were observed in the localization of DATI312F or DAT-D421N compared with WT. (B) Confocal live imaging of transfected CAD cells. Cells were stained with the fluorescent cocaine analog JHC 1-64 $(10 \mathrm{nM})$ to obtain specific labeling of DAT present in the plasma membrane. While cells expressing WT, DAT-I312F, or both DAT-I312F and DAT-D421N achieved clear membrane labeling with $10 \mathrm{nM}$ of JHC 1-64, no membrane labeling was observed in cells expressing the DAT-D421N mutant alone. (C) Upon labeling of transfected CAD cells with $300 \mathrm{nM}$ JHC1-64, both WT and DATD421N-transfected cells showed clear membrane labeling, which was not observed when cells were preincubated with $1 \mu \mathrm{M}$ nomifensine, a selective blocker of DAT (D). Images shown are representative of 3 independent experiments. Images of WT and mutants were taken with identical settings. to cotransport 2 sodium ions during each transport cycle $(49,50)$. Binding of these sodium ions is believed to have a critical role in promoting both substrate binding and binding of cocaine analogs by stabilizing the transporter in an outward-facing conformation $(5,32,51-53)$. Moreover, mutation of Thr354 in LeuT, which is the residue corresponding to Asp421 in hDAT, has been shown to contribute to the stabilization of LeuT in an inward-facing conformation (32). It is therefore conceivable that DAT-D421N is predominantly inward facing, leading to a dramatic decrease in apparent dopamine affinity and thereby an impairment of uptake. Impaired sodium binding to $\mathrm{Na} 2$ might also explain the efflux data showing a reverse effect of amphetamine. Instead of inducing dopamine-MPP ${ }^{+}$efflux, as in WT DAT, we observed that amphetamine treatment of cells expressing DAT-D421N produced a decline in the amperometric current as well as a decline in $\mathrm{MPP}^{+}$ efflux, suggesting that amphetamine blocks a constitutive, anom- alous leak of substrate through DAT-D421N. The predicted switch in the conformational equilibrium of DAT-D $421 \mathrm{~N}$ to an inwardfacing configuration might favor constitutive efflux of dopamine, and under these conditions, amphetamine may act as an inhibitor rather than an inducer of efflux. Indeed, we observed a similar decline in amperometric signal as well as a decline in baseline $\left[{ }^{3} \mathrm{H}\right]-\mathrm{MPP}^{+}$efflux following cocaine treatment of DAT-D421Nexpressing cells compared with treatment of WT DAT-expressing cells. A similar constitutive anomalous dopamine efflux has been reported for the DAT missense mutation DAT-A559V, identified in a bipolar patient and in 2 brothers with ADHD, and for DAT-T356M, identified in a patient with autism spectrum disorder $(24,54)$. Importantly, cocaine-sensitive anomalous dopamine efflux has been demonstrated in dopaminergic neurons from DAT-KO mice transfected with DAT-A559V, and a preliminary characterization of DAT-A559V knock-in mice reported elevated 


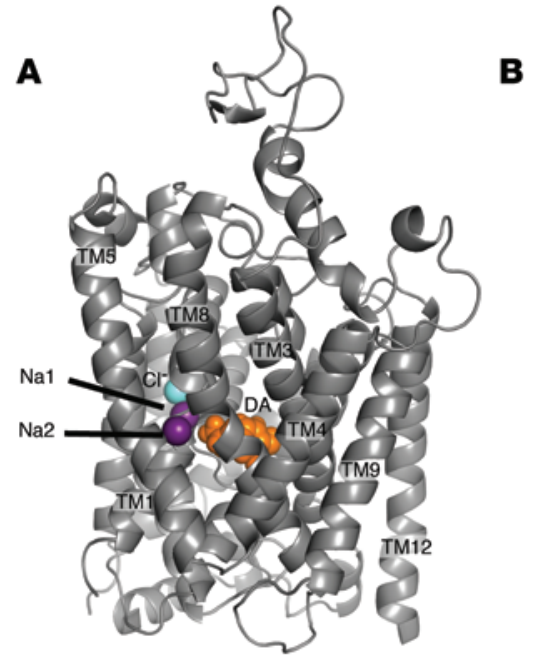

D

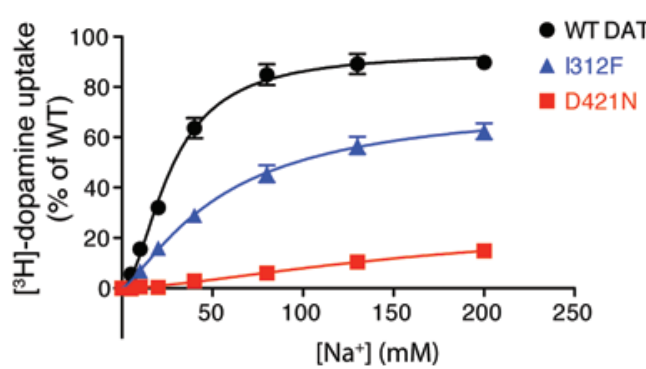

B

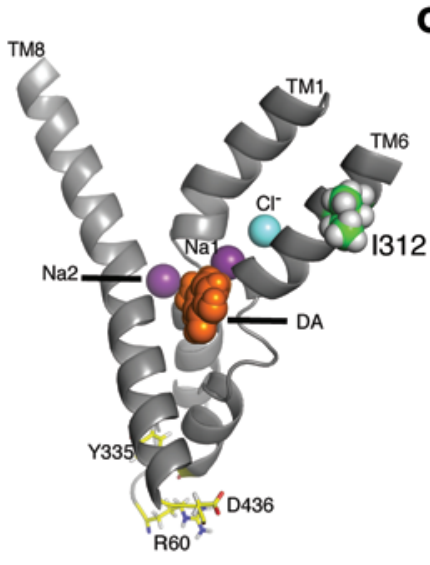

C

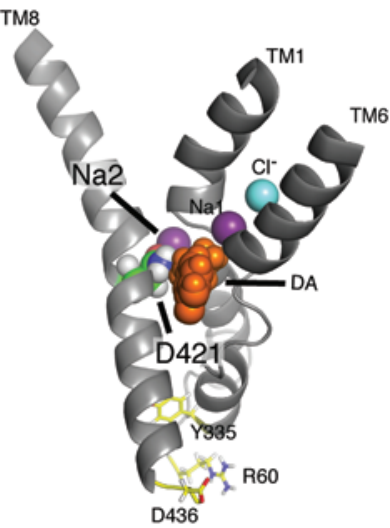

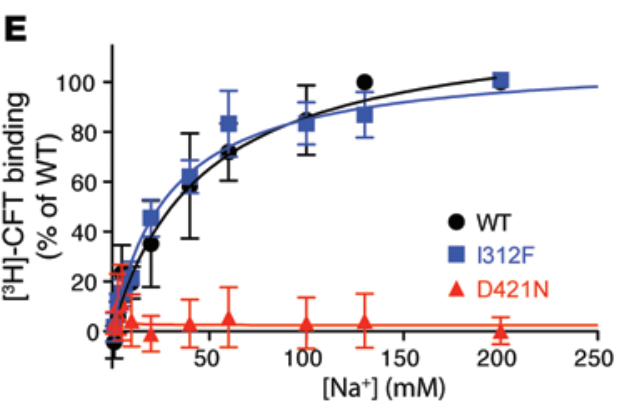

Figure 6

Molecular modeling of hDAT. (A) Homology model of hDAT based on the outward-open crystal structure of LeuT, a bacterial homolog. (B) I312, indicated in green in TM 6, was seen to have no direct contact with dopamine or ion binding sites. (C) D421, indicated in green in TM 8, was involved in coordinating binding of sodium at the second sodium binding site (Na2). Sodium and chloride ions are indicated in purple and turquoise, respectively. (D) Sodium dependence of $\left[{ }^{3} \mathrm{H}\right]$-dopamine uptake. Dopamine uptake was evaluated at increasing concentrations of sodium. The sodium dependence of DAT-I312F-mediated uptake was comparable to that of WT $\left(K_{d}=70 \pm 20 \mathrm{mM}\right.$ for DAT-I312F vs. $K_{d}=30 \pm 4 \mathrm{mM}$ for WT). DAT-D421N, on the other hand, showed impaired binding of sodium, seen as a linear sodium dependence curve with no tendency to saturate at $200 \mathrm{mM}$ of $\mathrm{NaCl}$. (E) Sodium dependence of [ $\left.{ }^{3} \mathrm{H}\right]$-CFT binding. Sodium dependence of $\left[{ }^{3} \mathrm{H}\right]$-CFT binding to DAT-I312F was similar to that of WT $\left(K_{d}=29 \pm 3.6 \mathrm{mM}\right.$ for DAT-I312F vs. $K_{d}=46 \pm 10 \mathrm{mM}$ for WT), while specific binding of [ $\left.{ }^{3} \mathrm{H}\right]-\mathrm{CFT}$ to DAT-D421N could not be detected. The curves of $\mathbf{D}$ and $\mathbf{E}$ are average curves from 3 and 4 experiments, respectively, each performed in triplicate and normalized to WT $\mathrm{B}_{\text {max }}$. ChoCl was used for equimolar cation substitution of sodium to obtain indicated sodium concentrations. $\mathrm{B}_{\max }$ and $K_{\mathrm{d}}$ values were derived using a onesite-specific binding model.

extracellular dopamine levels $(55,56)$. Thus, anomalous efflux can even occur in native systems with an intact vesicular dopamine storage system. The identification of anomalous dopamine efflux via DAT-D421N provides additional support to the suggestion that this efflux produced by DAT-coding variants is a potential risk factor in psychiatric disorders $(24,54)$. The present data might also support the notion that alterations in DAT function or expression levels in general could be a risk factor in ADHD, as indicated by several previous studies (57). It is nevertheless important to note that the patients carrying DAT-A559V and DAT$\mathrm{T} 356 \mathrm{M}$ were heterozygous and that the mutants possessed larger or unaffected dopamine uptake capacities compared with those of DAT-D421N. These patients would therefore be expected to have considerable residual DAT function despite anomalous dopamine efflux, and motoric dysfunctions were not reported for the DATA559V and DAT-T356M carriers $(21,24,54)$.

The mechanism by which inadequate and/or altered DAT function can lead to parkinsonian symptoms remains unresolved (58, 59). Indeed, the reduced uptake capacity of both DAT-I312F and
DAT-D $421 \mathrm{~N}$ is likely of key importance for the dopaminergic dysfunction of the patient, but given the generally much more pronounced phenotype of DAT-D421N, we cannot exclude that the majority of alterations underlying the clinical presentation of the patient can be ascribed to DAT-D421N. It is nonetheless clear that the predicted decreased DAT function will compromise dopamine reuptake and thereby prevent transmitter reuse as well as impair clearance of released dopamine. In addition, impaired dopamine clearance might inhibit dopamine synthesis through overstimulation of presynaptic dopamine $\mathrm{D}_{2}$ autoreceptors and cause downregulation of postsynaptic dopamine receptors (58, 59). In DAT-KO mice, however, presynaptic $\mathrm{D}_{2}$ receptors are downregulated and $\mathrm{TH}$ is upregulated $(60,61)$, which could argue against the involvement of TH inhibition via $\mathrm{D}_{2}$ activation in humans with compromised DAT function. In spite of this, severe dopamine deficiency may develop and inadvertently lead to motoric dysfunction and appearance of parkinsonian symptoms. Interestingly, the majority of DAT-KO mice show a hyperdopaminergic behavioral phenotype and do not display parkin- 
A

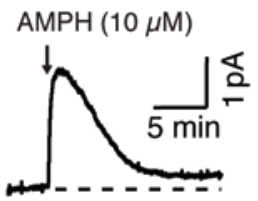

WT

B

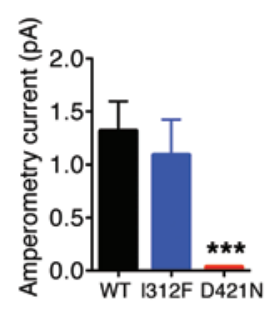

E

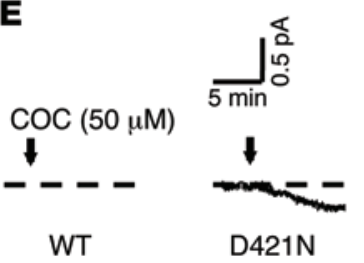

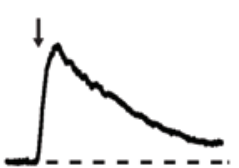

I312F

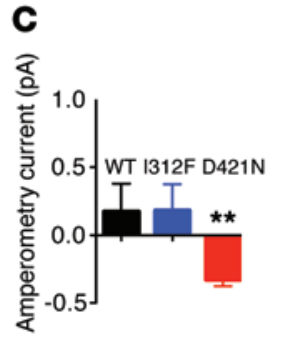

$\mathbf{F}$

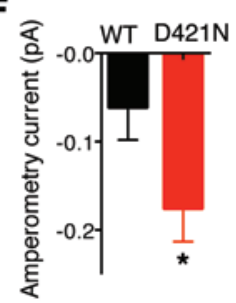

$\downarrow$

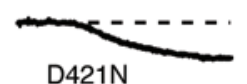

D

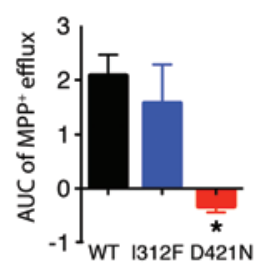

G

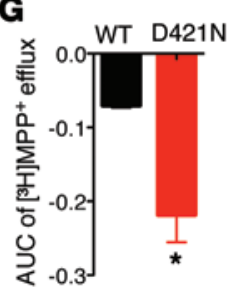

Figure 7

Amphetamine- and cocaine-induced amperometric currents and MPP+ efflux. HEK293 cells were transiently transfected with WT, DAT-I312F, or DAT-D421N. (A) Representative amperometric currents; arrows indicate the application of amphetamine $(10 \mu \mathrm{M})$. (B) Quantification of the amphetamineinduced peak amperometric currents. (C) Amperometric data are reported as the amphetamine-induced amperometric current recorded 10 minutes after amphetamine application. Data are the means $\pm S E M$; $n=7-9$. ${ }^{* *} P<0.01$ and ${ }^{* *} P<0.001$ by Mann-Whitney $U$ test. (D) Quantification of amphetamine-induced $\left[{ }^{3} \mathrm{H}\right] \mathrm{MPP}{ }^{+}$efflux presented as the AUC of MPP+ efflux. $\left[{ }^{3} \mathrm{H}\right] \mathrm{MPP}+$ release was calculated by subtracting the basal release from total release during the first 8 minutes following amphetamine exposure. Data are the means \pm SEM; $n=4-5$. ${ }^{*} P<0.025$ by Mann-Whitney $U$ test. (E) Representative amperometric currents following cocaine exposure $(50 \mu \mathrm{M})$ of HEK293 cells transiently expressing WT DAT or DAT-D421N. (F) Amperometric data are reported as the cocaineinduced amperometric current 10 minutes after cocaine application. Data are the means \pm SEM; $n=3 .{ }^{*} P<0.05$ by 1 -tailed $t$ test. (G) Quantification of cocaine-induced $\left.{ }^{3} \mathrm{H}\right] \mathrm{MPP}+$ efflux presented as the AUC of MPP+ efflux. Cocaine treatments led to a significantly higher reduction in MPP+ efflux from cells expressing DAT-D421N compared with WT. ${ }^{*} P<0.05$ by Mann-Whitney $U$ test, consistent with a constitutive leak of dopamine.

sonian features, except after blockade of dopamine synthesis by inhibition of TH (12). A subpopulation of the mice sporadically develops progressive motor dysfunction with eventual paralysis and death, but this phenotype has been attributed to loss of GABAergic neurons rather than of dopaminergic neurons (13). The discrepancy between humans and mice could indicate that DAT is even more important for sustaining a sufficient pool of releasable dopamine in humans, but could also be related to the time course of the disease, because the maximum time of exposure to the dysfunctional uptake would be 18-24 months in mice compared with years in humans. Nevertheless, the level of remaining DAT uptake capacity is likely crucial for whether dopamine deficiency will develop and, accordingly, when parkinsonian symptoms become apparent. It is also possible that the constitutive, anomalous substrate efflux, mediated by DAT-D421N, contributes to dopaminergic dysregulation by further reducing intraneuronal stores of dopamine.

Another potentially important phenotypic property of DAT-D $421 \mathrm{~N}$ is a large cation leak identified by our electrophysiological analyses. This leak is likely linked to the impaired sodium binding to $\mathrm{Na} 2$, thereby supporting a key role of $\mathrm{Na} 2$ in governing cation permeability of the transporter. Interestingly, previous studies have indicated that the uncoupled substrate-induced current in DAT can affect neuronal excitability (42), suggesting that DAT-mediated currents are sufficiently large to impact neuronal function. The leak in DAT-D421N is markedly larger than the substrate-induced current of the WT. Thus, the current might contribute to the dopaminergic dysregulation. Given the large amount of DAT protein believed to be expressed in dopaminergic neurons, one could also speculate that the dopaminergic neurons become more vulnerable as a consequence of the stress enforced by the leak, which could implicate the leak in the neurodegenerative component of the patient's disease. Note that there is indirect evidence for a potentially harmful effect of cation influx, as blocking sodium influx via sodium channels and the $\mathrm{Na}^{+} / \mathrm{H}^{+}$exchangers has been shown in several cases to have a neuroprotective effect $(62,63)$.

Our findings provided strong evidence for dopaminergic neurodegeneration in the patient studied. Comparison of DAT-SPECT scans performed 8 years apart (2005 and 2013) revealed a sizable loss of [123I]-FP-CIT-binding capacity (from $35 \%$ to $\sim 15 \%$ of normal capacity). It is unlikely that this loss was a consequence of gradually decreased expression of mutant DATs in otherwise intact dopaminergic neurons; rather, it indicates a neurodegenerative component with progressive loss of dopaminergic pathways. Such a neurodegenerative component was supported by striatal volumetric measurements based on a $\left[{ }^{18} \mathrm{~F}\right]-F D G$ PET/MRI scan, which showed reduced volumes of the caudate nuclei, in accordance with previous findings (64). The neuronal loss might also explain why we do not see an increased ratio between the dopamine metabolite HVA and the serotonin metabolite 5HIAA in CSF, as reported in children with DAT deficiency syndrome $(14,15)$. Notably, some studies report reduced HVA levels in the CSF of Parkinson's patients $(65,66)$, arguing that the normal, not decreased, HVA value of our patient reflects a relative increase in the accumulation and degradation of extraneuronal dopamine as compared with the putative numbers of remaining neurons. Moreover, residual activity of the DAT mutants carried by the proband would also be expected to oppose extracellular dopamine accumulation compared with patients with no DAT expression. Specialized diagnostic laboratories should therefore be aware that for some individuals with DAT mutations, an unremarkable CSF profile might be recorded. Interpretation, in conjunction with clinical details, is therefore essential.

In summary, we describe here what we believe to be the first link between DAT missense mutations and early-onset parkinsonism in adults. Furthermore, the neuropsychiatric comorbidity of the proband strongly supports the notion that complex DAT geno-/phe- 
A
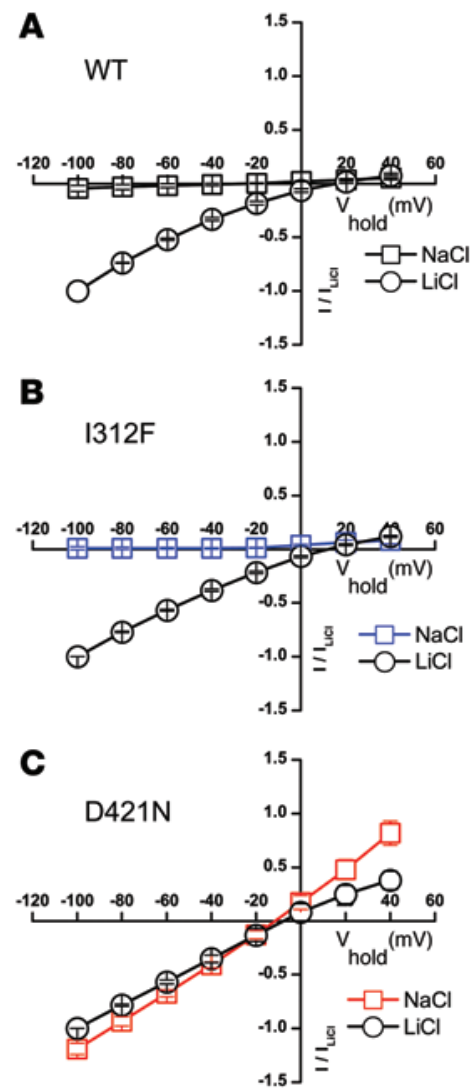

notype correlations might contribute significantly to different dopaminergic pathologies. Thus, the present findings should provide a critical basis for further exploration of how dopaminergic dysfunction and altered DAT function contribute to brain disorders.

\section{Methods}

Subject and procedures. We included 91 unrelated patients from a referral-based hospital cohort. The patients were referred for genetic testing due to early-onset parkinsonism or a related atypical movement disorder. One patient underwent further assessment due to identification of mutations in SLC6A3. Previous and updated results from medical files were obtained. Video recordings at the present time were made, and CSF neurotransmitter analysis and a supplementary DAT-SPECT scan were performed. CSF concentrations of HVA and 5HIAA were measured by HPLC, as described, and compared with age-related, laboratory-specific ranges $(67,68)$. DAT-SPECT scans were acquired 3-4 hours after administration of an average i.v. bolus of $180 \mathrm{MBq}$ of the DAT ligand ${ }^{123} \mathrm{I}-2 \beta$-carbometoxy$3 \beta$-[4-iodophenyl]-N-[3-fluoropropyl]nortropane ([123I]FP-CIT; GE Healthcare). The ratio of specifically bound radioligand to nondisplaceable radioligand was used as a measure of DAT availability. DAT-SPECT scans were acquired with an interval of 8 years on 2 different SPECT scanners. Hence, the individual scans, acquired on the respective scanners, were compared with the average DAT availability in a group of age-matched healthy controls. A 10-minute simultaneous PET/MR scan was performed 40 minutes after i.v. injection of $200 \mathrm{MBq}\left[{ }^{18} \mathrm{~F}\right]-\mathrm{FDG}$ on a fully integrated PET/MR (3T) system (Biograph mMR; Siemens Healthcare). Anatomical imaging using T1 was performed as follows: 3D magnetization-prepared rapid gradient echo (MPRAGE) sequence with a repetition time (TR) of $1,900 \mathrm{~ms}$, an echo time (TE) of $2.44 \mathrm{~ms}$, a flip angle of $9^{\circ}$, a voxel size of

\section{Figure 8}

DAT-D421N possesses a cocaine-sensitive cation leak in sodium. (A-C) I/V diagrams of the cocaine-sensitive steady-state currents (control - cocaine) in sodium chloride ( $\mathrm{NaCl}$; squares) and lithium chloride ( $\mathrm{LiCi}$, circles) for WT (A), DAT-I312F (B), and DAT-D421N (C). WT and mutant constructs were expressed in Xenopus oocytes and analyzed by the 2-electrode voltage clamp technique as described in Methods. The $\mathrm{I} / \mathrm{V}$ diagrams were generated in $20-\mathrm{mV}$ steps from -100 to $+40 \mathrm{mV}$. The currents are normalized to the maximum current in lithium at a membrane potential of $-100 \mathrm{mV}(\mathrm{WT},-402 \pm 59 \mathrm{nA}$; DAT-I312F, $-175 \pm 27 \mathrm{nA}$; DAT-D421N $219 \pm 31 \mathrm{nA}$; means $\pm \mathrm{SEM} ; n=4-6)$.

$1.0 \times 1.0 \times 1.0 \mathrm{~mm}^{3}$, and an acquisition time of 5 minutes. Anatomical imaging using T2 was performed as follows: turbo spin echo (TSE) sequence, with a TR of $6,000 \mathrm{~ms}$, a TE of $96 \mathrm{~ms}$, a flip angle of $150^{\circ}$, a voxel size of $0.7 \times 0.7 \mathrm{~mm}^{2}$, a slice thickness of $4 \mathrm{~mm}$, and an acquisition time of 1.25 minutes. The $\left[{ }^{18} \mathrm{~F}\right]$-FDG PET scan was attenuation corrected using lowdose CT scanning (69) and compared with a database of healthy subjects (Scenium 3.0, Syngo-Via; Siemens Healthcare). Volumetric measurements using Freesurfer version 5.2.0 were performed from T1 MPRAGE MRI images of the caudate nuclei, putamina, and the intracranial volume and compared with a group of healthy age-matched subjects exposed to identical imaging procedures and analyses.

Sequencing. DNA was purified using standard methods. Coding regions of the SLC6A3 gene were amplified by PCR using exon-specific primers (Supplemental Table 1). PCR products were sequenced using the BigDye Terminator v3.1 Cycle Sequencing Kit (Applied Biosystems) and analyzed on an ABI 3100 capillary sequencer (Applied Biosystems).

SNP analysis. Two hundred Danish controls and the patient were subjected to SNP analysis. The probes used were custom-made by Life Technologies to target the variants c.934A $>\mathrm{T}$ and c.1261G $>$ A. The analysis was done using the TaqMan SNP Genotyping Assay (Life Technologies) and was performed according to the manufacturer's instructions.

Site-directed mutagenesis. cDNA encoding the hDAT mutants DAT-I312F and DAT-D421N were made on a PRC/CMV hDAT background using the QuikChange site-directed mutagenesis kit (Stratagene). Constructs were verified by DNA sequencing.

Cell culture and transient transfection. Human embryonic kidney 293 (HEK293) cells and COS-7 cells were maintained as previously described $(70,71)$. Cath.-a-differentiated (CAD) cells from a catecholaminergic cell line were grown in media composed of 50\% DMEM and 50\% Ham's F-12 nutrient mixture (all from Invitrogen) at $37^{\circ} \mathrm{C}$ in a humidified incubator with $5 \%$ $\mathrm{CO}_{2}$. All media were supplemented with $1 \%$ penicillin-streptomycin. Transient transfections were performed using Lipofectamine 2000 (Invitrogen), Fugene-6 (Roche Molecular Biochemicals, for amperometry data), or Lipofectamine Plus (Invitrogen, for superfusion assay), according to the manufacturers' protocols, using a 3:1 transfection reagent/DNA ratio. Assays were conducted 24-48 hours after transfection.

$\left[{ }^{3} \mathrm{H}\right]$-dopamine uptake. Saturation kinetics of dopamine uptake in HEK293 cells were determined using a 2-fold dilution row (final concentrations of 6.4-0.05 $\mu \mathrm{M}$ ) with constant specific activity. The dilution row was composed of a mixture of $[2,5,6]\left({ }^{3} \mathrm{H}\right)$-dopamine (PerkinElmer) and unlabeled dopamine (Sigma-Aldrich), essentially as described in ref. 72. Briefly, transiently transfected HEK293 cells were seeded onto 24-well plates $(175,000$ cells per well) coated with polyornithine. On the day of the experiment (48 hours after transfection), cells were washed once in uptake buffer (25 mM HEPES, $120 \mathrm{mM} \mathrm{NaCl}, 5 \mathrm{mM} \mathrm{KCl}, 1.2 \mathrm{mM} \mathrm{CaCl}_{2}$, and $1.2 \mathrm{mM} \mathrm{MgSO} 4$ supplemented with $5 \mathrm{mM}$ D-glucose, $1 \mathrm{mM}$ ascorbic acid, and $1 \mu \mathrm{M}$ of the catechol-O-methyltransferase [COMT] inhibitor Ro 41-0960, pH 7.4) and equilibrated in uptake buffer for 15 minutes at room 
temperature (RT). Uptake was initiated by the addition of the dilution row mixture and terminated after 5 minutes (at RT) by washing twice in ice-cold uptake buffer. Cells were lysed in 1\% SDS and transferred onto 24-well counting plates (PerkinElmer). Scintillation fluid was added, and the radioactivity was measured in a Wallac MicroBeta TriLux Liquid Scintillation Counter (PerkinElmer). Nonspecific binding was determined using cells transfected with a similar amount of empty plasmid. $K_{\mathrm{m}}$ and $\mathrm{V}_{\max }$ values were derived by fitting Michaelis-Menten kinetics to the background-corrected uptake data using GraphPad Prism 5.0 (GraphPad Software). All determinations were performed in triplicate.

Sodium dose-response curves were obtained by equimolar titration of $200 \mathrm{mM} \mathrm{NaCl}$ in anion substitution buffer $(250 \mathrm{mM}$ Tris-HEPES, $50 \mathrm{mM}$ K-gluconate, $12 \mathrm{mM} \mathrm{Mg-gluconate,} \mathrm{and} 12 \mathrm{mM}$ Ca-gluconate, $\mathrm{pH}$ 7.4) against $\mathrm{ChoCl}$ in anion substitution buffer to obtain final $\mathrm{Na}^{+}$concentrations of $200,130,80,40,20,10,5$, and $0 \mathrm{mM}$. These solutions were supplemented with $5 \mathrm{mM}$ D-glucose, $1 \mathrm{mM}$ ascorbic acid, and $1 \mu \mathrm{M}$ of the COMT inhibitor. Transfected HEK293 cells were washed in wash buffer (200 mM Cho-gluconate in anion substitution buffer) and equilibrated for 10 minutes in the denoted sodium buffers. Uptake was initiated by addition of a dopamine mixture of unlabeled dopamine and $[2,5,6]$ $\left({ }^{3} \mathrm{H}\right)$-dopamine to obtain a final dopamine concentration of $6.4 \mu \mathrm{M}$. Uptake was allowed for 5 minutes (WT DAT) or 10 minutes (mutants) and terminated by washing twice in ice-cold wash buffer. Cell lysing, transfer, and counting were carried out as described above. Nonspecific binding was determined using cells transfected with an equivalent amount of plasmid vector without insert. $K_{\mathrm{m}}$ values and maximum uptake $\left(\mathrm{V}_{\max }\right)$ were derived in GraphPad Prism 5.0.

$\left[{ }^{3} \mathrm{H}\right]$-CFT binding. Binding assays were carried out as described previously (73) on intact COS-7 cells or HEK293 cells using $\left[{ }^{3} \mathrm{H}\right] 2 \beta$-carbomethoxy-3 $\beta$ (4-fluorophenyl)tropane (CFT) $(76.6 \mathrm{Ci} / \mathrm{mmol}$; PerkinElmer) as radioligand. Cells were washed once in ice-cold binding buffer $(25 \mathrm{mM}$ HEPES, $130 \mathrm{mM} \mathrm{NaCl}, 5.4 \mathrm{mM} \mathrm{KCl}, 1.2 \mathrm{mM} \mathrm{CaCl}_{2}, 1.2 \mathrm{mM} \mathrm{MgSO}_{4}, 1 \mathrm{mM}$ L-ascorbic acid, $5 \mathrm{mM}$ D-glucose, and $1 \mu \mathrm{M}$ Ro 41-0960 [Sigma-Aldrich], $\mathrm{pH}$ 7.4). Unlabeled CFT was added at the concentrations indicated in Figure 3D and Supplemental Figure 2, followed by addition of $\left[{ }^{3} \mathrm{H}\right]$-CFT $(2-5 \mathrm{nM})$. Cells were then incubated at $5^{\circ} \mathrm{C}$ for approximately $100 \mathrm{~min}$ utes to reach equilibrium, and the assay was terminated by washing twice in ice-cold binding buffer. Transfer and counting were performed as described above. Data were fitted by nonlinear regression using GraphPad Prism 5.0 to calculate maximum bimding $\left(\mathrm{B}_{\max }\right)$ and affinity $\left(K_{\mathrm{d}}\right)$. Sodium dependency curves of $\left[{ }^{3} \mathrm{H}\right]$-CFT binding were performed as described for the $\left[{ }^{3} \mathrm{H}\right]$-dopamine uptake assay, though cells were incubated for approximately 100 minutes with $\left[{ }^{3} \mathrm{H}\right]$-CFT in the sodium concentrations indicated in Figure 6. Nonspecific binding was determined with $1 \mu \mathrm{M}$ nomifensine (Sigma-Aldrich).

Surface biotinylation. Surface biotinylation experiments were carried out essentially as described previously (28). Briefly, HEK293 cells were seeded in 6-well plates (500,000 cells per well) and transfected with $0.25 \mu \mathrm{g}$ DNA per well the following day. Twenty-four hours after transfection, cells were washed in ice-cold PBS (pH 7.4) and incubated with biotin for 40 minutes on ice $(1 \mathrm{mg} / \mathrm{ml}$ in PBS), followed by 2 washes in glycine and PBS (100 mM) and 2 washes in PBS. Cells were lysed in solubilization buffer $(25 \mathrm{mM}$ Tris, $\mathrm{pH} 7.5$, containing $150 \mathrm{mM} \mathrm{NaCl}, 1 \%$ Triton X-100, $0.2 \mathrm{mM}$ phenylmethylsulfonyl fluoride, and complete protease inhibitor cocktail; Roche). Lysates were centrifuged for 20 minutes $(16,000 \mathrm{~g})$. Supernatants were collected, and equal amounts of protein were loaded on avidin beads and left overnight at $4^{\circ} \mathrm{C}$. The avidin beads were pelleted by centrifugation and washed 4 times with solubilization buffer. Protein was eluted in $2 \times$ loading buffer containing $100 \mathrm{mM}$ DTT and incubated at $37^{\circ} \mathrm{C}$ for 30 minutes. Total lysates were likewise incubated for 30 minutes with $2 \times$ loading buffer con- taining $100 \mathrm{mM}$ DTT. Avidin beads were removed by filtration. Equal volumes of samples were separated by SDS-PAGE, and DAT was detected as described for Western blotting.

Cell lysate preparation and Western blot analysis. Transiently transfected HEK293 cells were washed twice in ice-cold PBS and lysed in solubilization buffer ( $25 \mathrm{mM}$ Tris, $\mathrm{pH} 7.5$, containing $150 \mathrm{mM} \mathrm{NaCl}, 1 \%$ Triton $\mathrm{X}-100,0.2 \mathrm{mM}$ PMSF, and complete protease inhibitor cocktail; Roche). The lysates were incubated at $4{ }^{\circ} \mathrm{C}$ for 20 minutes with end-over-end rotation, followed by a 20 -minute centrifugation at $16,000 \mathrm{~g}$. Protein concentration in the supernatant was determined using a BCA Protein Assay Kit (Pierce Biotechnology). The supernatant was mixed with $4 \times$ SDS loading buffer containing $100 \mathrm{mM}$ DTT and incubated for 30 minutes at $37^{\circ} \mathrm{C}$. An equal amount of protein was separated by SDS-PAGE (using Any kD Gels from Bio-Rad) and transferred to Immobilon-P membranes (Millipore). Membranes were blocked for 1 hour in blocking buffer (PBS containing $0.05 \%$ Tween- 20 and $5 \%$ dry milk) and incubated with primary rat anti-DAT antibody (1:1,000, MAB369; Millipore) in blocking buffer for 1 hour at RT or overnight at $4^{\circ} \mathrm{C}$. Membranes were then washed 3 times in PBS containing 0.05\% Tween-20 and incubated for 1 hour with secondary HRP-coupled goat anti-rat antibody (1:4,000 in blocking buffer). After washing, the blots were visualized by chemiluminescence (ECL kit; Amersham Biosciences) using AlphaEase (Alpha Innotech) and quantified with ImageJ software (NIH). To verify equal protein loading, membranes were reprobed for $\beta$-actin (Sigma-Aldrich).

Immunocytochemistry and JHC 1-64 live imaging of DAT. Immunocytochemical staining for DAT in transiently transfected CAD cells or HEK293 cells was performed using an N-terminal primary antibody (rat-anti DAT 1:1,000, MAB 369; Millipore) and Alexa Fluor 488 as a secondary antibody (goat anti-rat, 1:500), as described previously (72). For live imaging of DAT with $10 \mathrm{nM}$ or $300 \mathrm{nM} \mathrm{JHC} \mathrm{1-64,} \mathrm{cells} \mathrm{were} \mathrm{grown}$ in polyornithine-coated 2-well Lab-Tek chambers (Nunc). The procedure was carried out as described previously (72). As a control for DAT specificity, cells were preincubated for 20 minutes with $1 \mathrm{mM}$ nomifensine. Confocal microscopy analysis was performed using a Zeiss LSM 510 confocal laser-scanning microscope (Carl Zeiss) with an oil-immersion $63 \times 1.4$ numerical aperture objective (Carl Zeiss). Alexa Fluor 488 dye was excited with a 488 -nm laser line from an argon-krypton laser, and detection of the emitted light was done using a 505- to 530-nm bandpass filter. JHC 1-64 was excited with a 543-nm helium-neon laser, and fluorescence was recorded using a 560-nm long-pass filter. Images were combined using ImageJ software.

Molecular modeling and simulations. The molecular models for hDAT were constructed with MODELLER 9v10 (74) program and based on either the recent outward-open crystal structure of the bacterial member of the NSS family LeuT (PDB code: 3TT1) and the sequence alignment detailed previously (75), or on the recently published dDAT structure (PDB code: 4M48) (76). The substrate, dopamine, was positioned in the binding site by aligning the amine group and the hydrophobic portion with those of the substrate in the LeuT structure (77). The final model also included $2 \mathrm{Na}^{+}$ions positioned equivalently to those in LeuT and a $\mathrm{Cl}^{-}$ion coordinated by residues Asn82, Tyr102, Ser321, and Asn353 of DAT, based on the chloride binding site described previously $(78,79)$. For the MD simulation of DAT models, we prepared a lipid bilayer model composed of the following mixture of neutral lipids: $60 \%$ palmitoyl-oleoyl-phosphatidylcholine (POPC) (shared equally on the upper and lower leaflets), 25\% 1-palmitoyl-2-oleoylphosphatidylethanolamine (POPE) (on the lower leaflet), 5\% $\mathrm{PIP}_{2}$, and 10\% sphingomyelin (SGM), shown to be essential for DAT binding to the membrane (80). Thus, the simulated system, composed of the DAT model immersed in an explicit representation of the water/lipid bilayer/water environment, was constructed with the VMD software and equilibrated using NAMD software version 2.7 (81) and the all- 
atom CHARMM27 force field. The simulated system, including the transporter embedded in a membrane patch and water layers on each side containing $\mathrm{Na}^{+}$and $\mathrm{Cl}^{-}$ions (corresponding to a concentration of $150 \mathrm{mM} \mathrm{NaCl}$ ), was composed of approximately 340,000 atoms in a box with final dimensions of $168 \times 165 \times 153 \AA$ (at the end of 100 ns of free equilibration).

During the equilibration of the DAT model in its environment, the backbones were initially fixed and then harmonically constrained, and water was restrained by small forces from penetrating the protein-lipid interface. The constraints were released in 3 steps of $300 \mathrm{ps}$ each, changing the force constants gradually from 1 to $0.5 \mathrm{kcal} / \mathrm{mol} \AA 2$ and $0.1 \mathrm{kcal} / \mathrm{mol} \AA 2$, respectively. A constant temperature $(310 \mathrm{~K})$ was maintained with Langevin dynamics, and $1 \mathrm{~atm}$ constant pressure was achieved by using the hybrid Nosé-Hoover Langevin piston method on a flexible periodic cell (35).

To model the mutant DAT construct with D421N, the mutation was introduced with an FEP carried out with NAMD in the system described above and as described in detail previously $(34,35)$. According to this protocol, the coupling parameter $\lambda$ in the FEP computation was varied from 0 to 1 , such that each window did not exceed $3 \mathrm{kcal} / \mathrm{mol}$. In general, the hysteresis tests did not exceed $1 \mathrm{kcal} / \mathrm{mol}$ between annihilation and creation.

Amperometry. Transiently transfected HEK293 cells plated on 35-mm dishes were washed with Krebs-Ringer HEPES (KRH) buffer $(130 \mathrm{mM}$ $\mathrm{NaCl}$, $4.8 \mathrm{mM} \mathrm{KCl}, 2.2 \mathrm{mM} \mathrm{CaCl}$, $1.1 \mathrm{mM} \mathrm{MgSO} 4,1.2 \mathrm{mM} \mathrm{KH} 2 \mathrm{PO} 4$, and $25 \mathrm{mM}$ HEPES, $\mathrm{pH} 7.4$ ) containing $10 \mathrm{mM}$ D-glucose, $100 \mu \mathrm{M}$ pargyline, $1 \mathrm{mM}$ tropolone, and $100 \mu \mathrm{M}$ ascorbic acid and were incubated with $1 \mu \mathrm{M}$ dopamine in $\mathrm{KRH}$ buffer for 20 minutes at $37^{\circ} \mathrm{C}$. Cells were then washed 3 times with the external bath recording solution $(130 \mathrm{mM}$ $\mathrm{NaCl}, 10 \mathrm{mM}$ HEPES, $34 \mathrm{mM}$ D-glucose, $1.5 \mathrm{mM} \mathrm{CaCl}_{2}, 0.5 \mathrm{mM} \mathrm{MgSO}_{4}$, and $1.3 \mathrm{mM} \mathrm{KH}_{2} \mathrm{PO}_{4}$ ). Dopamine was measured by amperometric (oxidation) currents using a carbon fiber electrode (5 $\mu \mathrm{m}$; Dagan Corporation). The electrode was positioned in apposition to the plasma membrane and held at $+700 \mathrm{mV}$ with respect to the bath ground (a potential greater than the oxidizing potential of dopamine). Data were recorded using Axopatch 200B (sampling rate, $100 \mathrm{~Hz}$ ) with a low-pass 8-pole Bessel filter $(10 \mathrm{~Hz})$. For display only, traces were resampled at $10 \mathrm{~Hz}$ and digitally filtered offline at $1 \mathrm{~Hz}$.

Superfusion assays. HEK293 cells were grown in DMEM supplemented with $5 \%$ FBS. Cells were grown on poly-D-lysine-coated glass coverslips in 6-well plates and transiently transfected with plasmids encoding WT hDAT, DAT-I312F, or DAT-D421N. Prior to the experiment, $0.2 \mu \mathrm{M}$ of the radioactive-labeled DAT substrate $\mathrm{MPP}^{+}$was added to the cells and incubated for 60 minutes (DAT-D421N) or 30 minutes (WT and DAT-I312F) at $37^{\circ} \mathrm{C}$. The coverslips were transferred to small superfusion chambers (volume $=0.2 \mathrm{ml}$ ) and superfused with KRH buffer (composition: $25 \mathrm{mM}$ HEPES-NaOH, pH 7.4, $120 \mathrm{mM} \mathrm{NaCl}, 5 \mathrm{mM} \mathrm{KCl}, 1.2 \mathrm{mM} \mathrm{CaCl}_{2}$, and $1.2 \mathrm{mM} \mathrm{MgSO}_{4}$ supplemented with $5 \mathrm{mM} \mathrm{D}$-glucose) at RT at a rate of $0.7 \mathrm{ml}$ per minute for 45 minutes to establish a stable efflux line (equal to basal efflux). After the basal efflux had stabilized, the experiment was started with the collection of fractions every second minute. After 6 minutes, D-amphetamine $(3 \mu \mathrm{M})$ was added to the buffer. Finally, the remaining radioactivity was recovered by superfusing the cells for 6 minutes with $1 \%$ SDS. Tritium in the superfusate fractions and in the SDS lysates was determined by liquid scintillation counting. The release of $\left[{ }^{3} \mathrm{H}\right]$-labeled substrate was expressed as a fractional rate (i.e., the radioactivity released during a fraction was expressed as a percentage of the total radioactivity present in the cells at the beginning of that fraction). Drug-induced release was calculated by subtracting the estimated basal release from total release during the first 8 minutes of drug exposure and is expressed as a percentage of radioactivity in the cell at the beginning of drug exposure.

Electrophysiology on oocytes. The hDAT WT and mutant constructs were subcloned into the pFROG oocyte vector (82). The constructs were linearized using MluI, and cRNA was transcribed using the mMESSAGEmMACHINE kit (Ambion). Purified RNA was injected into defolliculated Xenopus oocytes (EcoCyte Bioscience). Oocytes were maintained in KULORI buffer $(88 \mathrm{mM}$ $\mathrm{NaCl}, 1 \mathrm{mM} \mathrm{MKCl}, 1 \mathrm{mM} \mathrm{MgCl}_{2}, 1 \mathrm{mM} \mathrm{CaCl}_{2}$, and $5 \mathrm{mM}$ HEPES-Tris, $\mathrm{pH}$ 7.4) at $18^{\circ} \mathrm{C}$. On the day of recording, oocytes were placed in a recording chamber, and currents were measured using conventional 2-electrode voltage clamp. The oocytes were penetrated by 2 micropipettes backfilled with $2 \mathrm{M} \mathrm{KCl}$. Oocytes were voltage clamped using a Dagan CA-1B clamp and digitized using Digidata 1440A (Molecular Devices) controlled with pClamp 10 (Axon Instruments). The oocytes were clamped at $-60 \mathrm{mV}$ and stepped from $-100 \mathrm{mV}$ to $+40 \mathrm{mV}$ in $+20-\mathrm{mV}$ increments. The membrane potential was held for $250 \mathrm{~ms}$ and measured relative to an extracellular $\mathrm{Ag}-\mathrm{AgCl}$ electrode connected to the recording chamber with an agarose- $2 \mathrm{M} \mathrm{KCl}$ bridge. The penetrated oocytes were gravity perfused with $\mathrm{NaCl}$ solution $(130 \mathrm{mM}$ $\mathrm{NaCl}, 2.5 \mathrm{mM} \mathrm{KCl}, 1.8 \mathrm{mM} \mathrm{CaCl}_{2}, 1 \mathrm{mM} \mathrm{MgCl}$, and $1 \mathrm{mM}$ HEPES-Tris, $\mathrm{pH}$ 7.4). For cation substitution experiments, the $130 \mathrm{NaCl}$ was substituted with equimolar amounts of LiCl. Steady-state currents in the presence of cocaine $(500 \mu \mathrm{M})$ were plotted as $\left(\mathrm{I}_{\text {buffer }}-\left(\mathrm{I}_{\text {buffer }}+\mathrm{COC}\right)\right)$. No cocaine-sensitive leak was observed in the uninjected oocytes.

Statistics. Unless otherwise stated, we have applied a 1-sample $t$ test. For all datasets in which WT DAT was compared with more than 1 mutant, the significance level $\alpha$ was adjusted to account for multiple tests. We applied the Bonferroni's correction, $\alpha_{\text {adj }}=\alpha / n$, with $n$ being the number of individual tests and $\alpha=0.05$. Thus, the significance level was set at $P<0.025$ when performing 2 individual comparisons and $P<0.0166$ when performing 3 individual tests.

Study approval. Patients were included from a referral-based hospital cohort, and sequencing of SLC6A3 in patients was approved by the Danish Regional Committee on Biomedical Research Ethics (Copenhagen, Denmark). Informed consent was obtained from the proband prior to any further investigations.

\section{Acknowledgments}

We thank all the patients and their relatives for participating in this study. We thank Lone Rosenquist for excellent technical assistance and Mu-Fa Zou for synthesizing JHC 1-64. The work was supported by grants from the NIH (P01 DA012408, to A. Galli, H. Weinstein, and U. Gether and DA035263 to A. Galli); the Danish Medical Research Council (to U. Gether); the University of Copenhagen BioScaRT Program of Excellence (to U. Gether); the Lundbeck Foundation Center for Biomembranes in Nanomedicine (to U. Gether); the Lundbeck Foundation (to L.B. Møller and U. Gether); the Novo Nordisk Foundation (to U. Gether); Fabrikant Vilhelm Pedersen og Hustrus Mindelegat (to U. Gether); the Austrian Science Fund (FWF) (F3506, to H.H. Sitte), and the Canadian Institutes of Health Research (CIHR) Postdoctoral Fellowship (to M.A. Sahai). Computational support was provided by the National Science Foundation Terascale Computing System at the Texas Advanced Computing Center (TG-MCB130180 and TG-MCB120073) and by the computer facilities at the Institute of Computational Biomedicine of Weill Cornell Medical College.

Received for publication October 18, 2013, and accepted in revised form April 24, 2014.

Address correspondence to: Ulrik Gether, Molecular Neuropharmacology and Genetics Laboratory, Department of Neuroscience and Pharmacology, The Faculty of Health and Medical Sciences, University of Copenhagen, DK-2200 Copenhagen N, Denmark. Phone: 45.2384.0089; Fax: 45.3532.7610; E-mail: gether@sund.ku.dk. 
1. Iversen SD, Iversen LL. Dopamine: 50 years in perspective. Trends Neurosci. 2007;30(5):188-193.

2. Gainetdinov RR, Caron MG. Monoamine transporters: from genes to behavior. Annu Rev Pharmacol Toxicol. 2003;43:261-284.

3. Torres GE, Gainetdinov RR, Caron MG. Plasma membrane monoamine transporters: structure, regulation and function. Nat Rev Neurosci. 2003; 4(1):13-25.

4. Sotnikova TD, Beaulieu JM, Gainetdinov RR, Caron MG. Molecular biology, pharmacology and functional role of the plasma membrane dopamine transporter. CNS Neurol Disord Drug Targets. 2006;5(1):45-56.

5. Kristensen AS, et al. SLC6 neurotransmitter transporters: structure, function, and regulation. Pharmacol Rev. 2011;63(3):585-640.

6. Jones SR, Gainetdinov RR, Jaber M, Giros B, Wightman RM, Caron MG. Profound neuronal plasticity in response to inactivation of the dopamine transporter. Proc Natl Acad Sci U S A. 1998;95(7):4029-4034.

7. Gainetdinov RR, Wetsel WC, Jones SR, Levin ED, Jaber M, Caron MG. Role of serotonin in the paradoxical calming effect of psychostimulants on hyperactivity. Science. 1999;283(5400):397-401.

8. Zhuang $X$, et al. Hyperactivity and impaired response habituation in hyperdopaminergic mice. Proc Natl Acad Sci U S A. 2001;98(4):1982-1987.

9. Leo D, Gainetdinov RR. Transgenic mouse models for ADHD. Cell Tissue Res. 2013;354(1):259-271.

10. Russell VA. Overview of animal models of attention deficit hyperactivity disorder (ADHD). Curr Protoc Neurosci. 2011; Chapter 9:Unit9.35.

11. Gainetdinov RR. Strengths and limitations of genetic models of ADHD. Atten Defic Hyperact Disord. 2010;2(1):21-30.

12. Sotnikova TD, Beaulieu JM, Barak LS, Wetsel WC, Caron MG, Gainetdinov RR. Dopamine-independent locomotor actions of amphetamines in a novel acute mouse model of Parkinson disease. PLoS Biol. 2005;3(8):e271.

13. Cyr M, et al. Sustained elevation of extracellular dopamine causes motor dysfunction and selective degeneration of striatal GABAergic neurons. Proc Natl Acad Sci U S A. 2003;100(19):11035-11040.

14. Kurian MA, et al. Homozygous loss-of-function mutations in the gene encoding the dopamine transporter are associated with infantile parkinsonism-dystonia. J Clin Invest. 2009;119(6):1595-1603.

15. Kurian MA, et al. Clinical and molecular characterisation of hereditary dopamine transporter deficiency syndrome: an observational cohort and experimental study. Lancet Neurol. 2011;10(1):54-62.

16. Sulzer D, Sonders MS, Poulsen NW, Galli A. Mechanisms of neurotransmitter release by amphetamines: a review. Prog Neurobiol. 2005;75(6):406-433.

17. Gizer IR, Ficks C, Waldman ID. Candidate gene studies of ADHD: a meta-analytic review. Hum Genet. 2009;126(1):51-90.

18. Cook EH Jr, et al. Association of attention-deficit disorder and the dopamine transporter gene. Am J Hum Genet. 1995;56(4):993-998.

19. Franke B, et al. The genetics of attention deficit/hyperactivity disorder in adults, a review. Mol Psychiatry. 2012;17(10):960-987.

20. Purper-Ouakil D, Ramoz N, Lepagnol-Bestel AM, Gorwood P, Simonneau M. Neurobiology of attention deficit/hyperactivity disorder. Pediatr Res. 2011;69(5 pt 2):69R-76R.

21. Mazei-Robison MS, Couch RS, Shelton RC, Stein MA, Blakely RD. Sequence variation in the human dopamine transporter gene in children with attention deficit hyperactivity disorder. Neuropharmacology. 2005;49(6):724-736

22. Sakrikar D, et al. Attention deficit/hyperactivity disorder-derived coding variation in the dopamine transporter disrupts microdomain targeting and trafficking regulation. J Neurosci. 2012;32(16):5385-5397.

23. Grünhage F, et al. Systematic screening for DNA sequence variation in the coding region of the human dopamine transporter gene (DAT1). Mol Psychiatry. 2000;5(3):275-282.

24. Hamilton PJ, et al. De novo mutation in the dopamine transporter gene associates dopamine dysfunction with autism spectrum disorder. Mol Psychiatry. 2013:18(12):1315-1323.

25 . Borghammer $P$, et al. Cortical hypometabolism and hypoperfusion in Parkinson's disease is extensive: probably even at early disease stages. Brain Struct Funct. 2010;214(4):303-317.

26. Hastrup H, Karlin A, Javitch JA. Symmetrical dimer of the human dopamine transporter revealed by cross-linking Cys-306 at the extracellular end of the sixth transmembrane segment. Proc Natl Acad SciU S A. 2001;98(18):10055-10060.

27. Daniels GM, Amara SG. Regulated trafficking of the human dopamine transporter. Clathrinmediated internalization and lysosomal degradation in response to phorbol esters. J Biol Chem. 1999;274(50):35794-35801

28. Bjerggaard C, et al. Surface targeting of the dopamine transporter involves discrete epitopes in the distal $\mathrm{C}$ terminus but does not require canonical PDZ domain interactions. $J$ Neurosci. 2004;24(31):7024-7036

29. Qi Y, Wang JK, McMillian M, Chikaraishi DM. Characterization of a CNS cell line, CAD, in which morphological differentiation is initiated by serum deprivation. J Neurosci. 1997;17(4):1217-1225.

30. Eriksen J, et al. Visualization of dopamine transporter trafficking in live neurons by use of fluorescent cocaine analogs. J Neurosci. 2009; 29(21):6794-6808.

31. Cha JH, et al. Rhodamine-labeled $2 \beta$-car-

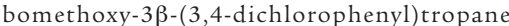
analogues as high-affinity fluorescent probes for the dopamine transporter. J Med Chem. 2005; 48(24):7513-7516.

32. Krishnamurthy H, Gouaux E. X-ray structures of LeuT in substrate-free outward-open and apo inward-open states. Nature. 2012;481(7382):469-474.

33. Penmatsa A, Wang KH, Gouaux E. X-ray structure of dopamine transporter elucidates antidepressant mechanism. Nature. 2013;503(7474):85-90.

34. Zhao C, Stolzenberg S, Gracia L, Weinstein $\mathrm{H}$, Noskov S, Shi L. Ion-controlled conformational dynamics in the outward-open transition from an occluded state of LeuT. Biophys J. 2012; 103(5):878-888.

35. Shi L, Quick M, Zhao Y, Weinstein H, Javitch JA. The mechanism of a neurotransmitter:sodium symporter - inward release of $\mathrm{Na}^{+}$and substrate is triggered by substrate in a second binding site. Mol Cell. 2008;30(6):667-677.

36. Khoshbouei H, Wang H, Lechleiter JD, Javitch JA, Galli A. Amphetamine-induced dopamine efflux. A voltage-sensitive and intracellular $\mathrm{Na}^{+}$-dependent mechanism. J Biol Chem. 2003;278(14):12070-12077.

37. Sulzer D. How addictive drugs disrupt presynaptic dopamine neurotransmission. Neuron. 2011; 69(4):628-649.

38. Fog JU, et al. Calmodulin kinase II interacts with the dopamine transporter $\mathrm{C}$ terminus to regulate amphetamine-induced reverse transport. Neuron. 2006;51(4):417-429.

39. Sitte HH, Huck S, Reither H, Boehm S, Singer EA, Pifl C. Carrier-mediated release, transport rates, and charge transfer induced by amphetamine, tyramine, and dopamine in mammalian cells transfected with the human dopamine transporter. J Neurochem. 1998;71(3):1289-1297.

40. Sonders MS, Zhu SJ, Zahniser NR, Kavanaugh MP, Amara SG. Multiple ionic conductances of the human dopamine transporter: the actions of dopamine and psychostimulants. J Neurosci. 1997;17(3):960-974.

41. Meinild AK, Sitte HH, Gether U. Zinc potentiates an uncoupled anion conductance associated with the dopamine transporter. J Biol Chem. 2004;279(48):49671-49679.

42. Ingram SL, Prasad BM, Amara SG. Dopamine transporter-mediated conductances increase excitability of midbrain dopamine neurons. Nat Neurosci. 2002;5(10):971-978.

43. Girard SL, Dion PA, Rouleau GA. Schizophrenia genetics: putting all the pieces together. Curr Neurol Neurosci Rep. 2012;12(3):261-266.

44. Veltman JA, Brunner HG. De novo mutations in human genetic disease. Nat Rev Genet. 2012;13(8):565-575

45. Gratten J, Visscher PM, Mowry BJ, Wray NR. Interpreting the role of de novo protein-coding mutations in neuropsychiatric disease. Nat Genet. 2013;45(3):234-238

46. Crosiers D, Theuns J, Cras P, Van Broeckhoven C. Parkinson disease: insights in clinical, genetic and pathological features of monogenic disease subtypes. J Chem Neuroanat. 2011;42(2):131-141.

47. Puschmann A. Monogenic Parkinson's disease and parkinsonism: clinical phenotypes and frequencies of known mutations. Parkinsonism Relat Disord. 2013;19(4):407-415

48. Ng J, et al. Dopamine transporter deficiency syndrome: phenotypic spectrum from infancy to adulthood. Brain. 2014;137(4):1107-1119.

49. Gu H, Wall SC, Rudnick G. Stable expression of biogenic amine transporters reveals differences in inhibitor sensitivity, kinetics, and ion dependence. J Biol Chem. 1994;269(10):7124-7130.

50. McElvain JS, Schenk JO. A multisubstrate mechanism of striatal dopamine uptake and its inhibition by cocaine. Biochem Pharmacol. 1992;43(10):2189-2199.

51. Schmitt KC, Rothman RB, Reith ME. Nonclassical pharmacology of the dopamine transporter: atypical inhibitors, allosteric modulators, and partial substrates. J Pharmacol Exp Ther. 2013;346(1):2-10.

52. Beuming T, et al. The binding sites for cocaine and dopamine in the dopamine transporter overlap. Nat Neurosci. 2008;11(7):780-789.

53. Claxton DP, et al. Ion/substrate-dependent conformational dynamics of a bacterial homolog of neurotransmitter:sodium symporters. Nat Struct Mol Biol. 2010;17(7):822-829.

54. Mazei-Robison MS, et al. Anomalous dopamine release associated with a human dopamine transporter coding variant. J Neurosci. 2008; 28(28):7040-7046

55 . Bowton E, et al. Dysregulation of dopamine transporters via dopamine D2 autoreceptors triggers anomalous dopamine efflux associated with attention-deficit hyperactivity disorder. J Neurosci. 2010;30(17):6048-6057.

56. Gowrishankar R, Hahn MK, Blakely RD. Good riddance to dopamine: roles for the dopamine transporter in synaptic function and dopamine-associated brain disorders. Neurochem Int. 2013;pii: S0197-0186(13)00289-1.

57. Fusar-Poli P, Rubia K, Rossi G, Sartori G, Balottin U. Striatal dopamine transporter alterations in ADHD: pathophysiology or adaptation to psychostimulants? A meta-analysis. Am J Psychiatry. 2012;169(3):264-272.

58. Kurian MA, Gissen P, Smith M, Heales S Jr, Clayton PT. The monoamine neurotransmitter disorders: an expanding range of neurological syndromes. Lancet Neurol. 2011;10(8):721-733.

59. Blackstone C. Infantile parkinsonism-dystonia: a dopamine "transportopathy". J Clin Invest. 2009;119(6):1455-1458

60 . Jones SR, et al. Loss of autoreceptor functions in mice lacking the dopamine transporter. Nat Neurosci. 1999; 
2(7):649-655

61. Gainetdinov RR. Dopamine transporter mutant mice in experimental neuropharmacology. Naunyn Schmiedebergs Arch Pharmacol. 2008;377(4-6):301-313.

62. Yu XM. The role of intracellular sodium in the regulation of NMDA-receptor-mediated channel activity and toxicity. Mol Neurobiol. 2006;33(1):63-80.

63. Stys PK. General mechanisms of axonal damage and its prevention. J Neurol Sci. 2005;233(1-2):3-13.

64. Pitcher TL, et al. Reduced striatal volumes in Parkinson's disease: a magnetic resonance imaging study. Transl Neurodegener. 2012;1(1):17.

65. Lunardi $G$, et al. Correlation between changes in CSF dopamine turnover and development of dyskinesia in Parkinson's disease. Parkinsonism Relat Disord. 2009;15(5):383-389.

66. Ishibashi K, et al. Cerebrospinal fluid metabolite and nigrostriatal dopaminergic function in Parkinson's disease. Acta Neurol Scand. 2009;122(1):46-51.

67. Hyland K, Smith I, Howells D, Clayton P, Leonard $\mathrm{J}$. The determination of pterins, biogenic amine metabolites and aromatic amino acids in cerebrospinal fluid using isocratic reverse phase liquid chromatography with in series dual cell coulometric electrochemical and fluorescence detection: use in the study of inborn errors of dihydropteridine reductase and 5.10-methylenetetrahydrofolatye reductase. In: Biochemical and Clinical Aspects of Pteridines. New York, New York, USA: Walter de Gmyter; 1985;85-99.

68. Hyland K, Surtees RA, Heales SJ, Bowron A, Howells
DW, Smith I. Cerebrospinal fluid concentrations of pterins and metabolites of serotonin and dopamine in a pediatric reference population. Pediatr Res. 1993;34(1):10-14.

69. Andersen FL, et al. Combined PET/MR imaging in neurology: MR-based attenuation correction implies a strong spatial bias when ignoring bone. Neuroimage. 2014;84:206-216.

70. Rasmussen TN, Plenge P, Bay T, Egebjerg J, Gether U. A single nucleotide polymorphism in the human serotonin transporter introduces a new site for $\mathrm{N}$-linked glycosylation. Neuropharmacology. 2009;57(3):287-294.

71. Holst B, et al. PICK1 deficiency impairs secretory vesicle biogenesis and leads to growth retardation and decreased glucose tolerance. PLoS Biol. 2013;11(4):e1001542.

72. Rickhag M, et al. A C-terminal PDZ domain-binding sequence is required for striatal distribution of the dopamine transporter. Nat Commun. 2013;4:1580

73. Loland CJ, Grånäs C, Javitch JA, Gether U. Identification of intracellular residues in the dopamine transporter critical for regulation of transporter conformation and cocaine binding. J Biol Chem. 2004;279(5):3228-3238

74. Sali A, Blundell TL. Comparative protein modelling by satisfaction of spatial restraints. J Mol Biol. 1993;234(3):779-815.

75. Beuming T, Shi L, Javitch JA, Weinstein H. A com- prehensive structure-based alignment of prokaryotic and eukaryotic neurotransmitter $/ \mathrm{Na}^{+}$symporters (NSS) aids in the use of the LeuT structure to probe NSS structure and function. Mol Pharmacol. 2006;70(5):1630-1642.

76. Penmatsa A, Gouaux E. How LeuT shapes our understanding of the mechanisms of sodium-coupled neurotransmitter transporters. J Physiol. 2014;592(pt 5):863-869.

77. Shan J, Javitch JA, Shi L, Weinstein H. The substrate-driven transition to an inward-facing conformation in the functional mechanism of the dopamine transporter. PLoS One. 2011;6(1):e16350.

78. Zomot E, Bendahan A, Quick M, Zhao Y, Javitch JA, Kanner BI. Mechanism of chloride interaction with neurotransmitter:sodium symporters. Nature. 2007;449(7163):726-730.

79. Kantcheva AK, et al. Chloride binding site of neurotransmitter sodium symporters. Proc Natl Acad Sci US A. 2013;110(21):8489-8494.

80. Kiessling V, Wan C, Tamm LK. Domain coupling in asymmetric lipid bilayers. Biochim Biophys Acta. 2009;1788(1):64-71.

81. Phillips JC, et al. Scalable molecular dynamics with NAMD. J Comput Chem. 2005;26(16):1781-1802.

82. Günther W, Lüchow A, Cluzeaud F, Vandewalle A, Jentsch TJ. ClC-5, the chloride channel mutated in Dent's disease, colocalizes with the proton pump in endocytotically active kidney cells. Proc Natl Acad Sci US A. 1998;95(14):8075-8080. 